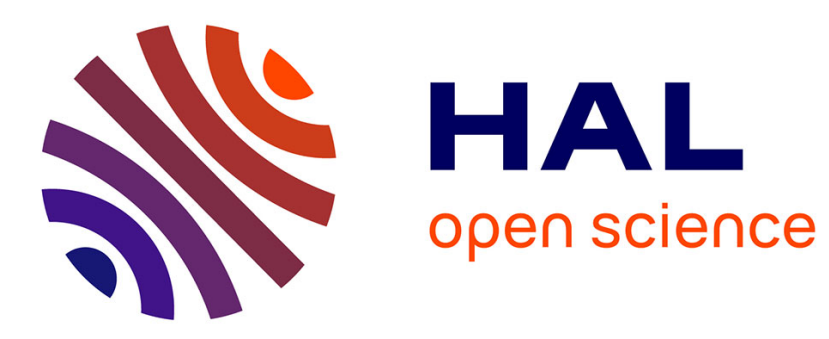

\title{
LES of an ignition sequence in a gas turbine engine
}

\author{
M. Boileau, G. Staffelbach, B. Cuenot, Thierry Poinsot, C. Berat
}

\section{To cite this version:}

M. Boileau, G. Staffelbach, B. Cuenot, Thierry Poinsot, C. Berat. LES of an ignition sequence in a gas turbine engine. Combustion and Flame, 2008, 154 (1-2), pp.2-22. hal-01981373

\section{HAL Id: hal-01981373 \\ https://hal.science/hal-01981373}

Submitted on 15 Jan 2019

HAL is a multi-disciplinary open access archive for the deposit and dissemination of scientific research documents, whether they are published or not. The documents may come from teaching and research institutions in France or abroad, or from public or private research centers.
L'archive ouverte pluridisciplinaire HAL, est destinée au dépôt et à la diffusion de documents scientifiques de niveau recherche, publiés ou non, émanant des établissements d'enseignement et de recherche français ou étrangers, des laboratoires publics ou privés. 


\title{
LES of an ignition sequence in a full helicopter combustor
}

\author{
M. Boileau ${ }^{\text {a,* }}$, G. Staffelbach ${ }^{\text {a }}$, B. Cuenot $^{\mathrm{a}}$, T. Poinsot $^{\mathrm{b}}$ and \\ C. Bérat ${ }^{\mathrm{c}}$ \\ ${ }^{\mathrm{a}}$ CERFACS, Toulouse, France \\ ${ }^{\mathrm{b}}$ IMFT - CNRS, Toulouse, France \\ ${ }^{\mathrm{c}}$ Turbomeca (SAFRAN group), Bordes, France
}

\begin{abstract}
Being able to ignite or reignite a gas turbine engine in a cold and rarefied atmosphere is a critical issue for many manufacturers. From a fundamental point of view, the ignition of the first burner and the flame propagation from one burner to another one are phenomena which are usually not studied. The present work is a Large Eddy Simulation (LES) of these phenomena. To simulate a complete ignition sequence in an annular chamber, LES has been applied to the full 360 degrees geometry including 18 burners. This geometry corresponds to a real gas turbine chamber. Massively parallel computing (700 processors on a Cray XT3 machine) was essential to perform such a large calculation. Results show that liquid fuel injection has a strong influence on the ignition times. Moreover, the rate of flame progress from burner to burner is much higher than the turbulent flame speed due to a major effect of thermal expansion. This flame speed is also strongly modified by the main burners aerodynamics due to the swirled injection. Finally, a variability of the combustor sectors and quadrants ignition times is highlighted.
\end{abstract}


Key words: turbulent combustion, ignition, two-phase flows, large eddy simulation, complex geometry, Euler-Euler approach

* Corresponding author.

Address: CERFACS, 42 av. G. Coriolis, 31057 Toulouse Cedex 1, France

Tel.: +33 (0)5 61193024

Fax: +33 (0)561 193030

E-mail: matthieu.boileau@cerfacs.fr 


\section{Introduction}

Ignition is a critical phase of all aero gas turbines. In aircraft engines, altitude reignition capability is an essential design constraint. In helicopter engines, where a fast and reliable lightup is needed for a wide range of altitudes, ignition can become a real difficulty because the combination of low pressure, low temperature and poor atomisation leads to expensive, complex and heavy ignition devices. A successful ignition sequence in a full engine requires typically three phases [1]:

- I - Energy deposition: in a first step, a hot gas kernel must be initiated. This can be achieved by using a spark plug, a laser shot or a secondary igniter producing a source of hot gases. Usually, the number of ignition systems is much smaller than the number of burners: in the helicopter engine studied here, two igniters are used to start combustion in a 18-burner combustor.

- II - Flame ignition: the hot gases produced by the igniter must evaporate the liquid fuel (if it is present), heat the gas and initiate the first flame in the burners surrounding the igniter.

- III - Propagation: after this first ignition, the flame front must move from one burner to the next one until all burners are active. Aero gas turbine chambers can contain 14 to 20 burners so that the combustion process in an isolated sector for one burner must be strong enough to start combustion in the neighbouring sectors. In some cases, this cannot be achieved without additional igniters.

Designing igniters for aero gas turbines is a difficult task because the prediction of each of these three phases is still a significant challenge for most compu- 
tational tools. A successful ignition requires a delicate adjustment between chamber and igniter devices in terms of igniter's power, position, number, etc. In most cases, trial and error processes must be used on full chamber experimental benches to determine adequate ignition systems. Some chambers/igniters combinations pass reasonably well Phase I but fail to ignite the neighbouring burners. Some others pass Phase II, ignite a few burners but then fail to ignite the whole chamber. In all cases, increasing the altitude makes all phases more difficult.

From a scientific point of view, studying the ignition of a full chamber in a gas turbine raises many new and exciting questions. Phase I is difficult but is also a rather academic question which can be studied in laboratory set-ups. Phases II and III are more difficult to study in academic set-ups. How a flame can "jump" from one burner to another one (Phase III) is a question which is seldom addressed in laboratories because most academic set-ups are limited to one sector for obvious reasons of cost. Therefore, developing prediction tools for all three phases of ignition is interesting but it is limited by two difficulties:

- The physics of ignition during Phase I is very complex: even in laminar premixed gaseous flows, many aspects of ignition are not understood yet. Adding liquid fuel turbulence makes the problem much more difficult. In laminar flows, the influences of spark energy [2-6], of the mean flow at the spark location [7,8], of detailed kinetics [9-11], of pressure [12] are still open questions. Most of these studies have been developed for perfectly premixed configurations while aero gas turbines (like Direct Injection piston or rocket engines) feature stratified flows, incomplete and unsteady mixing as well as evaporating sprays. Although experiments on ignition in stratified flows are now beginning [13], very few models are available for such configura- 
tions. Moreover, even though the extension of ignition models developed in laminar flows to turbulent cases is a classical investigation field in the combustion community, especially for piston engines [14-18], no present model for ignition in turbulent flows is really viewed as sufficient.

- During phases II and III, existing methods may be sufficient. For example Large Eddy Simulation for reacting flows have proved their accuracy in multiple configurations [19-24] including ignition or flashback cases where large flame movements must be tracked $[25,26]$. The main difficulty however is that LES must be applied to a full 360 degrees chamber and not to one sector as done usually. Actually, to the authors knowledge, this has never been done and although groups have reported LES computations in one sector coupled to compressor and turbine flows [27], no LES of a full combustion chamber including all sectors has been published yet. The only method to achieve such a simulation is to use massively parallel computing and this paper demonstrates that this is possible today.

The objective of this work is to present a first LES of an ignition sequence in the full combustion chamber of an helicopter gas turbine using massively parallel computing. The combustion chamber is a demonstrator called VESTA built by Turbomeca. It contains 18 injectors and uses two ignition devices which can be viewed as jets injecting hot burnt gases. An advantage of this type of igniters for LES is that Phase I phenomena (spark or laser induced first ignition) do not need to be modeled: within the combustion chamber where the LES is performed, only jets of hot gases are added to represent the igniters so that the present LES really focuses on Phases II and III of a full ignition sequence. 
The present LES is based on a compressible explicit solver [28-30], an EulerEuler model for the liquid fuel phase $[26,31,32]$, the Thickened Flame model [33-35] and a one-step chemical scheme for JP10/air combustion. The computation is performed on 700 processors on a Cray XT3 machine. Results allow to understand how the fuel evaporates, and the first flames ignite near the two igniters before propagating from one burner to the other. The topology of the flame during this propagation is described and the notion of flame leading point (LP) is introduced to follow the propagation of the flame front through the chamber. Propagation speeds of the LP are measured and the role of swirl is highlighted in the control of the trajectory of the LP and of its speed. The study also shows how complex the postprocessing of such three-dimensional flames in complex geometries may become.

The next section describes the LES method used for the simulation, recalls the conservation equations and the specificities of the computer implementation on massively parallel machines to be able to utilize up to 5000 processors with a 90 percent efficiency. The following section describes the configuration of the VESTA combustor while the last section presents the results in terms of flame topology, leading point position and speeds, front curvature, consumption speeds and ignition times of the various sectors.

\section{LES of two-phase reacting flows}

LES solver

The LES solver is a fully unstructured compressible code, including species transport and variable heat capacities [30]. It can work with both structured 
and unstructured grids which makes it easily applicable to complex geometries [36]. Centered spatial schemes and explicit time-advancement are used to control numerical dissipation and capture acoustics [29]. For the present case, a three-step Runge-Kutta method is employed with a time step controlled by the speed of sound. Sub-grid scale viscosity is defined by the WALE model, derived from the classic Smagorinsky model [37]. Sub-grid thermal and molecular fluxes are modeled using an eddy diffusion assumption with constant sub-grid Prandtl and Schmidt numbers respectively. As requested by the WALE model, a no-slip condition is applied at the wall. Characteristic boundary conditions NSCBC $[38,30]$ are used for all inlets and for the outlet.

Spray modeling

The modeling of the liquid phase in a LES solver is an important issue for which two classes of methods are available:

- the Euler-Lagrange description (EL) where the gaseous flow is modeled with an Eulerian method while the particles are tracked in a Lagrangian way ;

- the Euler-Euler description (EE) in which both the gaseous and dispersed phases are solved using an Eulerian formulation.

Several complex phenomena like polydisperse effects, droplet/wall interactions and crossing trajectories are easier to model with the EL approach. Thus, most existing studies of two-phase reacting flows in LES are based on a EL description of the spray [22,39-44]. However, following the individual trajectory of millions of droplet is far beyond the capacities of today's computers. To overcome this problem, physical particles are gathered into numerical parcels 
and modeling is required [45]. Another disadvantage of the EL method is the difficulty to optimize codes on massively parallel architectures (with several hundreds of processors). Figure 1 shows the number of particles per processor evaluated in the present calculation by integrating the Eulerian particle density on each partition of the computational domain. At the initial instant $t=0$, most of the 700 partitions contain less than 25000 particles while some partitions have more than 2 million particles. Moreover, this distribution changes during the calculation of the ignition sequence: the combustor is filled with droplets when ignition starts while the spray is only present in the near injector regions when the steady ignited regime is reached $(t=46 \mathrm{~ms})$. If such a simulation had been performed with an EL algorithm, preserving a high parallel efficiency would have required a re-partitioning of the domain during the computation with a complex and time-consuming dynamic load-balancing method [40].

The EE approach implementation is straightforward in terms of parallelization and allows to use the same data structure and algorithm for the dispersed and gaseous phases [46]. However, compared to the EL method, the initial modeling effort is large and difficulties may be encountered for sprays with extended size distributions [47]. Finally, from the numerical point of view, special care is needed to handle the resulting set of equations [48]. Recent work has demonstrated that the EE approach can be applied to LES of particle laden turbulent gas flows $[31,32,48-50]$. Boileau et al. [26] have evaluated the potential of such a methodology to simulate reacting flows in complex geometries and computed an ignition sequence inside a single sector of an aeronautical gas turbine combustor. In the present work, two-phase flow effects have been handled with the same EE approach and the reader is referred to this article for the modeling 
details. An important assumption is that the spray is fully atomized and has a single drop size distribution (monodisperse spray). A summary of the LES equations solved by the code is given below.

$$
\begin{aligned}
\text { Gaseous phase: } & \frac{\partial \overline{\mathbf{w}}}{\partial t}+\nabla \cdot \overline{\mathbf{F}} & =\overline{\mathbf{s}} \\
\text { Dispersed phase: } & \frac{\partial \overline{\mathbf{w}}_{l}}{\partial t}+\nabla \cdot \overline{\mathbf{F}}_{l} & =\overline{\mathbf{s}}_{l}
\end{aligned}
$$

where $\overline{\mathbf{w}}$ is the vector of gaseous conservative variables, $\overline{\mathbf{F}}$ is the flux tensor composed of viscous, inviscid and subgrid scale components and $\overline{\mathbf{s}}$ is the vector of source terms. $\overline{\mathbf{w}}$ and $\overline{\mathbf{s}}$ are given respectively by:

$$
\begin{gathered}
\overline{\mathbf{w}}=\left(\bar{\rho} \tilde{u}, \bar{\rho} \tilde{v}, \bar{\rho} \tilde{w}, \bar{\rho} \tilde{e}, \bar{\rho} \tilde{Y}_{k}\right) \\
\overline{\mathbf{s}}=\left(\bar{I}_{x}, \bar{I}_{y}, \bar{I}_{z}, \overline{\dot{\omega}}_{T}+\bar{I}_{i} \tilde{u}_{i}+\bar{\Pi}, \overline{\dot{\omega}}_{k}+\bar{\Gamma} \delta_{k F}\right)
\end{gathered}
$$

In Eq. $3, \bar{\rho}$ is the density, $(\tilde{u}, \tilde{v}, \tilde{w})$ are the velocity components, $\tilde{e}=\tilde{e}_{s}+1 / 2 \tilde{u}_{i} \tilde{u}_{i}$ is the total non chemical energy ( $\tilde{e}_{s}$ is the sensible energy) and $\tilde{Y}_{k}$ are the species mass fractions (the fuel species is noted $F$ ). In Eq. 4, combustion terms are the reaction rate $\overline{\dot{\omega}}_{k}$ and the heat release $\overline{\dot{\omega}}_{T}$ whose modeling is described in next section. Additional source terms representing exchanges between phases are the mass transfer $\bar{\Gamma}$, the momentum transfer $\bar{I}_{i}$ and the heat transfer $\bar{\Pi}$. In Eq. $2, \overline{\mathbf{w}}_{l}$ is the vector of conservative variables, $\overline{\mathbf{F}}_{l}$ is the flux tensor composed of convective and subgrid terms and $\overline{\mathbf{s}}_{l}$ is the vector of source terms. $\overline{\mathbf{w}}_{l}$ and $\overline{\mathbf{s}}_{l}$ are given respectively by:

$$
\begin{gathered}
\overline{\mathbf{w}}_{l}=\left(\rho_{l} \bar{\alpha}_{l}, \rho_{l} \bar{\alpha}_{l} \hat{u}_{l}, \rho_{l} \bar{\alpha}_{l} \hat{v}_{l}, \rho_{l} \bar{\alpha}_{l} \hat{w}_{l}, \rho_{l} \bar{\alpha}_{l} \hat{h}_{l}, \bar{n}_{l}\right) \\
\overline{\mathbf{s}}_{l}=\left(-\bar{\Gamma},-\bar{I}_{x},-\bar{I}_{y},-\bar{I}_{z},-\bar{\Pi}, 0\right)
\end{gathered}
$$

In Eq. $5, \rho_{l}$ is the liquid density, $\bar{\alpha}_{l}$ is the volume fraction, $\left(\hat{u}_{l}, \hat{v}_{l}, \hat{w}_{l}\right)$ are the spray velocity components, $\hat{h}_{l}$ is the sensible enthalpy and $\bar{n}_{l}$ is the droplet number density. This set of equations only describes the statistical average 
motion of the particles. The velocity deviation from this average, called random uncorrelated motion (RUM), describes the independent movement of each particle. The modeling of RUM as proposed for example in Ref. [32,51,52] is not yet satisfactory and Riber et al. $[32,52]$ have shown that RUM was not essential to capture the mean fields in a configuration representative of industrial flows. Moreover, no model is currently available to describe the effect of RUM on the flame front. Therefore, RUM has been omitted in the present application.

\section{Combustion modeling}

The fuel used for the LES is JP10, a substitute for kerosene that has similar thermochemical properties. The reaction rate $\overline{\dot{\omega}}_{k}$ is modeled by an Arrhenius law [20] with coefficients fitted from a detailed chemistry [53] to the present one-step irreversible chemistry: $\mathrm{JP} 10+14 \mathrm{O}_{2} \rightarrow 10 \mathrm{CO}_{2}+8 \mathrm{H}_{2} \mathrm{O}$, using criteria based on laminar flame speed and thickness. Figure 2 shows the comparison between the detailed chemistry and the simplified scheme for the prediction of the laminar flame speed $S_{L}$ and the adiabatic flame temperature $T_{2}$. The simplified scheme properly predicts the laminar flame speed for equivalence ratio less than 1.2 but overpredicts $S_{L}$ for rich flames. This error could be corrected by using a variable pre-exponential constant in the Arrhenius law [54]. Concerning the adiabatic flame temperature, predictions are correct only for equivalence ratio below 0.8 . For stoichiometric and rich regimes, the simplified chemistry overpredicts $T_{2}$ by about $200 \mathrm{~K}$. To reduce this error, a second reaction involving a secondary species and an equilibrium could be considered. However, for simplicity reason none of these additional modeling features are 
used in the present study. As a consequence, special attention should be paid if rich regimes are encountered.

To handle flame/turbulence interaction, the dynamically thickened flame model (TFLES) is used [55]. This model thickens the flame front by a factor $F$ so that it can be solved on the LES grid. The interaction between turbulence and chemistry at the subgrid level is modeled by the efficiency function $E$ which compensates the effect of thickening and accounts for the influence of turbulence on the subgrid turbulent flame speed. The TFLES model has been applied successfully in multiple configurations (premixed and partially premixed) and more detailed descriptions can be found in Ref. [19,55-57].

\section{Parallelism}

Thanks to the use of the MPI library, the LES code offers a very good efficiency on a high number of processors. Figure 3 from Staffelbach et al. [58] shows a linear scaling of the speed-up up to 4000 processors. Taking advantage of this feature, LES simulations has been performed on today's largest parallel computors [59-61]. The present calculation has been run on the Cray XT3 using 700 processors. This machine is equipped with 700 AMD bi-core Opteron 2.4 Ghz with a high-bandwith low-latency network. The whole ignition sequence took $112000 \mathrm{CPU}$ hours corresponding to 160 hours of execution time. The Eulerian algorithm for the spray represents less than $50 \%$ of the total computational cost and it allows to preserve a full parallel efficiency. 


\section{Configuration}

\section{Geometry and boundary conditions}

Figure 4 shows a view of the VESTA combustor. This annular chamber is divided in 18 identical sectors (see Fig. 5). For each sector, the kerosene spray is provided by an airblast main injector producing a swirled jet. The computing domain does not include the internal swirler geometry of these injectors: the imposed velocity profile at the injection outlet has been calibrated using a previous non reactive LES calculation in an extended domain of a single sector including the whole swirler geometry. The fuel spray is assumed to be fully atomized and the injection section used for the LES is located a few millimeters downstream of the real injector plane. Atomization and breakup mechanisms are replaced by a distribution of liquid load using $25 \mu \mathrm{m}$ diameter droplets. Figure 6 displays the air velocity and the spray mass flux profiles imposed at each burner outlet. This swirled flow leads to a classical vortex breakdown forming a strong central recirculation zone. As seen later, this back-flow is a key factor of the flame propagation and stabilization during ignition.

Cooling films and multi-perforated walls (present in the real combustor) are not included here for the sake of simplicity. Focusing on one single sector, Fig. 5 describes the conditions applied to the boundaries of the computing domain. The corresponding parameters are listed in Table 1. These physical conditions are not favourable for ignition in terms of air and fuel jets temperature and pression. However, they correspond to real starting conditions for a typical helicopter gas turbine (cold atmospheric air). The global equivalence ratio is: $\phi_{g}=1.5$. 
The objective is to understand how combustion is initiated in the main burners thanks to the energy released by the igniters. These igniters themselves are ignited electrically and can be modeled as hot jets. Figure $7 \mathrm{a}$ is a sketch in the C surface (see Fig. 9) that shows the location of an ignition injector between two main injectors. This pressurized injector generates a kerosene spray whose ignition produces a torch flame. Figure 7b describes how the burning spray has been replaced by a simple jet of hot gas. This gas is the combustion product of a stoichiometric kerosene/air mixture in terms of species composition $\left(\mathrm{CO}_{2}\right.$, $\mathrm{H}_{2} \mathrm{O}$ and $\mathrm{N}_{2}$ ) and temperature (adiabatic flame temperature). Injecting this inert gas at high temperature enables to provide some of the burner power, in the form of an enthalpy flux, without adding the complexity of the spark ignition of a fuel spray. The dynamic effect of this hot jet on the surrounding flow is rather low due the high density ratio between the hot gases and the fresh air. Thus, in order to mimic the spreading rate of the original flame due to the hollow cone spray (see Fig. 7a), a swirling component corresponding to a swirl number of 0.6 has been added. This value of the swirl number only induces a moderate spreading of the jet (and no vortex breakdown) because of the density ratio effect previously mentioned. Such swirl numbers are typical of the injectors used by Turbomeca.

Mesh

The entire domain has been meshed using tetrahedral cells with refined grids around the inlets and in the combustion zone. The final grid has been produced 
by replicating 18 times a single sector periodic grid leading to 19 million cells and 3.1 million nodes. Previous tests performed on a single burner domain have demonstrated that this mesh density was sufficient to capture the flame evolution.

\section{Initial conditions}

In the true ignition sequence, the igniters are started once fuel injection has been switched on in the main chamber and ignition occurs in a cold air flow mixed with liquid fuel droplets. To mimic this process, the initial flow condition is provided by the steady non-reacting air flow with liquid fuel injection. In this cold flow calculation, the physical conditions are the same as in Tab. 1 but the hot igniter jets are off. Due to the low temperature, the spray can hardly evaporate before the saturation conditions are reached. As a result the initial mean gaseous equivalence ratio is very low $\left(\phi_{\text {gas }}^{0}=0.0088\right)$ and most of the fuel is liquid. At the initial instant $t=0$, the hot jets are started and the ignition phase begins.

\section{Results and discussion}

\section{Flame topology}

Figure 8 labels the geometric entities of the annular combustor where analyses of the results are performed. The chamber geometry is perfectly symmetrical according to the $z$ and $y$ plane, so the annulus can be divided into four iden-

tical quadrants ( $Q 1$ to $Q 4)$. A corresponding azimuthal angle $\theta_{i}$ is defined for 
each of these quadrants. All eighteen sectors are identical except for $S 1 / S 18$ and $S 9 / S 10$ where the igniters $I 1$ and $I 2$ are placed. Actually, the swirling component of the main injectors condition (see previous section) removes a degree of symmetry of the flow. For instance, sector $S 1$ is really equivalent to sector $S 10$ but not to sectors $S 9$ and $S 18$. This effect has an impact on the azimuthal flame progress as will be seen later. Results will be plotted in the cutting surface $C$ defined on Fig. 8 and 9. It corresponds to a $20 \mathrm{deg}$. angle cone.

Figures 10 and 11 give a 3D view of the ignition sequence at four successive instants. The different cold air inlets are represented by the turquoise blue surfaces while the red surfaces point the two hot igniter jets. On surface $C$, the light blue regions exhibit the back-flow zones generated by each main injector (see Fig. 7). This color map shows that the large LES grid allows to resolve a great number of small turbulent structures. Time $t=14 \mathrm{~ms}$ corresponds to the ignition of the burners surrounding each igniters (referred as Phase II in introduction). From $t=19.2 \mathrm{~ms}$ to $t=46 \mathrm{~ms}$, the flame front (shiny light blue surface) is progressing from the first ignited sectors into the four quadrants of the annulus (Phase III). Once this front has gone through one sector (for example, at $t=29.2 \mathrm{~ms}$ ), the back-flow zone of this sector enables to stabilise the flame close to the main injector and primary air holes (see Fig. 5). As seen on surface $C$, the thermal expansion of the burnt gases produces a strong acceleration of the flow towards the outlet.

Figure 12 shows the temperature field and the flame front (iso-reaction rate) on the developped surface $C_{d e v}$ (Fig. 9) at various instants of the calculation. At $t=10 \mathrm{~ms}$, the hot gases created by the igniter $I 2$ start to interact with the main burner of sector $S 9$ while the reaction zone initiated by the igniter 
I2 stays close to the hot jet axis. $6 \mathrm{~ms}$ later, two phenomena are observed. In the downstream region of sectors $S 1, S 9, S 10$ and $S 18$, the reacting front has propagated in the axial and azimuthal directions leading to a "mushroomshaped" flame. At the same time, a flame has stabilised close to the $S 9$ and $S 18$ main injectors while the $S 1$ and $S 10$ ones are not ignited yet. From $t=16$ to $40 \mathrm{~ms}$, the reacting zone is progressing into the four quadrants filling the ignited sectors with hot gases. In quadrants $Q 1$ and $Q 3$, this front progresses faster in the downstream region of the chamber until $t=28 \mathrm{~ms}$. In quadrants $Q 2$ and $Q 4$, the flame propagating close to the main injectors is ahead of the downstream front since $t=22 \mathrm{~ms}$. Between $t=34$ to $40 \mathrm{~ms}$, the reaction progress is driven by the upstream front in all the quadrants. At $t=46 \mathrm{~ms}$, the flame fronts running from opposite directions and different igniters merge together, leading to the full ignition of all the main burners. Once ignited, each sector has two main reacting zones. The first one is a partially premixed flame located very close to the main injector outlet. It is stabilised by the recirculation zone created by the vortex breakdown of the swirled air jet. The second one is a diffusion flame located in the downstream region of the recirculation zone where the primary holes air jets (see Fig. 5) provide oxygen to burn the fuel excess from the upstream flame. Figure 12 shows clearly that the progress velocity of the flame is not identical in each quadrants: $Q 1$ and $Q 3$ are behind $Q 2$ and $Q 4$. This time delay begins at the ignition of the first main injector $(t=16 \mathrm{~ms})$ and increases until the end of the ignition sequence: the front merging occurs in sectors $S 4$ and $S 13$ whereas the mean azimuthal sectors (i.e. $\theta_{i}=90 \mathrm{deg}$.) are $S 5$ and $S 14$. This asymmetry is due to the swirling component of the main air jets (see above) and suggests that the velocity field plays a key role in the ignition process. This point is investigated further in the paper. 
Flame propagation mechanism

In order to follow the azimuthal propagation of the flame front into each quadrant of the combustor, a tracking method based on the temperature field is proposed. The idea is to define a point which characterizes the azimuthal instantaneous position of the flame in the annulus. In quadrant $Q_{i}$, this point, referred to as leading point (LP), is the maximum of the azimuthal angle $\theta_{i}$ (see Fig. 8) where the gas temperature is $1500 \mathrm{~K}$. This temperature level is located in the reacting zone and provides an estimate of the flame front position. Although the LP does not represent a physical entity, it can describe a front trajectory from which a characteristic front azimuthal velocity can be deduced. If $r_{L P}$ and $\theta_{L P}$ are the radial and azimuthal lagrangian coordinates of the leading point, the corresponding azimuthal speed of the LP is defined as: $V_{L P}=r_{L P} d \theta_{L P} / d t$.

A developed view of the LP in $Q 4$ is shown on Fig. 13d where the different phases of the ignition process may be identified. Before $t=12.8 \mathrm{~ms}$, the flame initiated by $I 1$ ignites the main injector of sector $S 18$. This phase corresponds to a slow and irregular progress of the LP with some backward movements. From $t=12.8$ to $21.4 \mathrm{~ms}$, the LP progresses faster through the downstream part of sectors $S 18$ then $S 17$. This phase is related to the initial "mushroomshaped" flame identified in the previous section (see Fig. 12). From $t=21.4$ to $36.4 \mathrm{~ms}$, the propagation mechanism changes and the fastest flame elements are now found near the injectors: the LP is located in the upstream (primary) zone of the combustor. In sectors $S 16$ and $S 15$, the $x$ position of the LP is modified by the presence of the main injectors air jets and recirculation zone. However, these $x$ oscillations are moderate and the LP progress is quite regular 
showing that the flame propagates in the primary zones of the injectors.

Figure 14 displays the same trajectory in a $x$ view of quadrant $Q 4$ and shows the three-phase process described above. From $t=12.8$ to $21.4 \mathrm{~ms}$, the downstream branch of the LP trajectory has a low radius due to the conical shape of the combustor. From $t=21.4$ to $36.4 \mathrm{~ms}$, the LP path stays close to the radial position of the main injectors axis. Only small deviations from this radius are observed. During this last phase, the LP has run more than $50 \mathrm{deg}$. of azimuthal angle while this evolution lasted only $1 / 3$ of the total time of the ignition sequence.

In order to investigate the parameters influencing the flame progress, the LP azimuthal absolute speed $V_{L P}$ and some flow properties at the LP location are plotted against the azimuthal position (Fig. 13). Fig. 13a shows that $V_{L P}$ varies between 2.4 and $17.4 \mathrm{~ms}$ with a mean value of $9.4 \mathrm{~ms}$. These values are much higher than a typical turbulent flame speed $\left(1\right.$ or $2 \mathrm{~m} . \mathrm{s}^{-1}$ in the present case, see later), revealing that the reacting front progress is not simply due to a turbulent flame propagation phenomena but is also controlled by an expansion effect like in spherical laminar [62] or turbulent flames [63]. According to Fig. 13a, $V_{L P}$ and the flow azimuthal velocity at $L P U_{\theta, L P}$ vary together and have the same sign. This indicates that the flame front is somehow carried by the flow. In addition to this Lagrangian view of the flame front, an Eulerian diagnostic is performed: flow temperature and azimuthal velocity are averaged over an azimuthal section leading to $\langle T\rangle_{\theta}$ and $\langle U\rangle_{\theta}$ respectively (see Fig. 15). Two control sections are chosen at $\theta_{4}=50$ and 70 deg., i.e. at the middle sections of sectors $S 16$ and $S 15$ respectively (see Fig. 8 and 14). On Fig. 15, the $\langle T\rangle_{\theta}$ rise corresponds to the flame front going through the section. For both $\theta_{4}$ values, the $\langle U\rangle_{\theta}$ curves clearly show that a positive mean azimuthal flow 
(a blow effect) is generated upstream the flame front. When the flame crosses each section, $\langle U\rangle_{\theta}$ becomes negative because of the burnt gases flow due to the thermal expansion across the flame front. The significant velocities observed in the fresh gases flow suggest that this thermal expansion phenomenon has a thrusting effect on the flame front. A way to quantify this effect is to perform a mass balance of the reaction products:

$$
\dot{m}_{p}=\dot{m}_{c o m b}+\dot{m}_{H J}-\dot{m}_{\text {out }}
$$

where $\dot{m}_{p}$ is the temporal variation of the total mass of products $\left(\mathrm{CO}_{2}+\mathrm{H}_{2} \mathrm{O}\right)$, $\dot{m}_{\text {comb }}$ is the total products reaction rate and $\dot{m}_{H J}$ and $\dot{m}_{\text {out }}$ are the mass flux of products through the hot igniter jets inlets and through the outlet respectively. Equation 7 means that the variation of the mass of products during ignition is a balance between production by chemical reaction and variations due to boundary fluxes. The time evolution of each term of Eq. 7 is displayed on Fig. 16. During the first $9 \mathrm{~ms}, \dot{m}_{p}$ is low and only due to the hot jets contribution. From 9 to $13 \mathrm{~ms}$, combustion starts and the reaction term $\dot{m}_{\text {comb }}$ strongly increases while the outlet flux $\dot{m}_{\text {out }}$ stays zero. This phase corresponds to the initial flame expansion from the two igniters before the burnt gases have reached the outlet (see Fig. 10, $t=14 \mathrm{~ms}$ ). From 13 to $33 \mathrm{~ms}$, burnt gases start to be ejected through the outlet and $\dot{m}_{\text {out }}$ grows at a rate similar to $\dot{m}_{c o m b}$ with a time delay of $5.2 \mathrm{~ms}$. This delay stays fairly constant and leads to a positive $\dot{m}_{p}$ oscillating between 6 and $10 \mathrm{~g} . \mathrm{s}^{-1}$. In the last phase (33 to $46 \mathrm{~m} . \mathrm{s}^{-1}$ ), the growing rate of $\dot{m}_{\text {comb }}$ decreases meaning that ignition is achieved and that the flow tends to a steady regime $\left(\dot{m}_{p} \rightarrow 0\right)$.

Considering that the increase of the burnt gases volume is related to the azimuthal front progress, a characteristic absolute displacement speed of the 
flame $V_{F}$ can be deduced from $\dot{m}_{p}$. If the flame front is seen as a thin and flat interface progressing in the azimuthal direction, $V_{F}$ is defined by:

$$
V_{F}=\frac{\dot{m}_{p}}{\rho_{p} A_{\theta}}
$$

where $\rho_{p}$ is the mean product $\left(\mathrm{CO}_{2}+\mathrm{H}_{2} \mathrm{O}\right)$ density in the burnt gases $\left(\rho_{p} \approx\right.$ $0.0677 \mathrm{~kg} \cdot \mathrm{m}^{-3}$ ) and $A_{\theta}$ is the area of the mean azimuthal section of the combustor. Another characteristic velocity of the flame is the consumption speed $\left\langle S_{c}\right\rangle$ defined as:

$$
\left\langle S_{c}\right\rangle=\frac{\dot{m}_{c o m b}}{\rho_{1} Y_{p, 2} A_{F}}
$$

where $\rho_{1}$ is the mass density of the fresh gases $\left(\rho_{1}=1.522 \mathrm{~kg} \cdot \mathrm{m}^{-3}\right), Y_{p, 2}$ is the mean product mass fraction in the burnt gases $\left(Y_{p, 2} \approx 0.270\right)$ and $A_{F}$ is the resolved flame front surface estimated by measuring the total area of the iso-surface of temperature $T=1500 K .\left\langle S_{c}\right\rangle$ provides an estimation of the sub-grid turbulent flame speed. Figure 17 compares these two global speeds $V_{F}$ and $\left\langle S_{c}\right\rangle$ and the mean leading point speed over the four quadrants $\left\langle V_{L P}\right\rangle_{Q}=$ $1 / 4 \sum_{i=1}^{4} V_{L P}(Q i)$. During the first $12 \mathrm{~ms},\left\langle S_{c}\right\rangle$ is not relevant since $A_{F}$ in Eq. 9 represents the initial hot jets boundary rather than a real flame front. From $t=12 \mathrm{~ms}$ to the end of the ignition sequence, $\left\langle S_{c}\right\rangle$ slightly increases but stays below $1 \mathrm{~m} . \mathrm{s}^{-1}$, i.e. of the order of a typical subgrid scale flame speed. Compared to this consumption speed, the absolute flame speed $V_{F}$ is one order of magnitude higher (around $7.5 \mathrm{~m} . \mathrm{s}^{-1}$ ) during the azimuthal flame spreading into the combustor $(12<t<46 \mathrm{~ms})$. This indicates that the burnt gases expansion is a major mechanism for flame propagation along the chamber. Figure 17 clearly shows the correlation between $V_{F}$ and the mean LP speed $\left\langle V_{L P}\right\rangle_{Q}$, confirming that $V_{F}$ is a relevant measure of the flame front progress speed. Finally, an azimuthal turbulent flame speed $\left\langle S_{c}\right\rangle_{\theta}$ has been estimated by integrating the products reaction rate along the propagating front and using 
the mean azimuthal section $A_{\theta}$ as a reference area. The ratio between $\left\langle S_{c}\right\rangle_{\theta}$ and the sub-grid flame speed $\left\langle S_{c}\right\rangle$ is the resolved flame wrinkling. Despite a typical measured value of 2 for this ratio, the consumption speed $\left\langle S_{c}\right\rangle_{\theta}$ stays much below the absolute flame speed $V_{F}$.

Figure 17 also shows that $V_{F}$ and $\left\langle V_{L P}\right\rangle_{Q}$ exhibit strong fluctuations: $\left\langle V_{L P}\right\rangle_{Q}$ may vary from 3 to $11 \mathrm{~m} . \mathrm{s}^{-1}$ between $t=12$ and $35 \mathrm{~ms}$. To check if local equivalence ratio fluctuations may be responsible for these fluctuations, Fig. 13c plots the equivalence ratio measured at LP $\left(\phi_{L P}\right)$ as a function of the azimuthal position. As expected, the variations of $\phi_{L P}$ influence the local fuel reaction rate $\dot{\omega}_{F, L P}$ (see Fig. 13b). Besides, the evolution of the evaporation rate $\Gamma_{L P}$ is fairly close to $\dot{\omega}_{F, L P}$, suggesting a strong coupling between the fuel spray evaporation and the chemical reaction. Further analyses of the effect of the dispersed phase on the flame structure are given in the next section. In sector S16, Fig. 13b and 13c exhibit a peak of $\phi_{L P}, \Gamma_{L P}$ and $\dot{\omega}_{F, L P}$. This behaviour is local and isolated: it occurs when the LP approaches the injector outlet (see Fig. 13d) where the liquid fuel mass loading is high. The sudden evaporation of this liquid produces a high fuel vapor concentration which boosts the reaction for a short time. However, this reaction peak and other variations of $\phi_{L P}, \Gamma_{L P}$ and $\dot{\omega}_{F, L P}$ do not appear to be correlated with the LP speed. This suggests that the fluctuations of the local flame front properties related to chemical reaction do not have a direct effect on the flame progress speed. Finally, the fact that such a peak does not appear at sector S15 shows that this effect results primarily of a transient and isolated change in the inner structure of the spray flame due to the turbulent flow.

Focusing on sectors $S 16$ and $S 15$ (where the LP evolves near the main injectors outlet, see Fig. 13d), a progress speed pattern comes out: the flame 
accelerates when approaching the injector axis then decelerates as it moves away (see Fig. 13a). This behaviour can be related to the convective effect of the recirculation zone. Figure 18 provides a view of the aerodynamic field obtained by a large eddy simulation of the cold flow in a single periodic sector (this flow is very similar to the initial condition used in the full-scale combustor calculation). The swirl injection leads to the strong and asymmetric vortex breakdown inducing a back-flow in the central region. The origin and the effects of this asymmetry are discussed later in the article. Though this view corresponds to a non reacting regime, a similar flow pattern has been observed during ignition: the strong eddy located on the left-hand side of the injector axis is still present, even when it meets the mean azimuthal flow due to the expansion effect previously mentioned. Figure 20a displays the reacting zone visualized by an iso-surface of temperature at $T=1500 \mathrm{~K}^{1}$ at successive instants from sector $S 16$ to $S 15$. Using this figure and its corresponding schematic view (Fig. 19), the following scenario provides a description of the mechanism influencing the flame progress from one sector to the next one:

- A - The reacting front is captured by the left-hand side vortex of sector $S 16$ (Fig. 19-A and 20a-A). On this side of the injector axis, the recirculating flow has the same direction as the flame normal and contributes to increase the LP speed (Fig. 20c). This acceleration is associated to an increase of the local flame front curvature $\gamma_{L P}$ (Fig. 20a-A and c).

- B - The air-spray mixture produced by the $S 16$ main injector is ignited (Fig. 19-B and 20a-B) but the flame progress is slowed down by the adverse recirculating flow on the right-hand side of the injector axis (Fig. 20c). As a

$\overline{1 \text { Tests }}$ have shown that visualizing the flame front using iso-surfaces of reaction rate or of temperature leads to the same conclusions 
result, the flame front takes a rounder shape (Fig. 20a-B) and $\gamma_{L P}$ decreases (Fig. 20c).

- C - As shown by Fig. 20b, the ignition of burner $S 16$ produces a continuous increase of the mean fuel reaction rate in this sector $\left(\left\langle\dot{\omega}_{F}\right\rangle_{S 16}\right)$. As mentioned above, the production of hot gases induces an expansion effect capable of thrusting the flame front. This effect contributes to the flame expansion illustrated by Fig. 19-C and 20a-C and by the local maximum of the LP speed observed at the boundary between sectors $S 16$ and $S 15$ (Fig. 20c).

Snapshots A' and B' of Fig. 20a show that a similar scenario is occurring later in sector $S 15$ and suggest that the above description represents a general process of the azimuthal flame front propagation in the combustor. Nevertheless, at later instants, Fig. 12 exhibits apparently a different behaviour: at $t=40 \mathrm{~ms}$, two reacting zones (sectors $S 13$ and $S 14$ ) seem to be separated from the main flame front. Figure 21 shows that this isolated flame is the result of the following process:

- At $t=34 \mathrm{~ms}$, the reacting zone coming from the injector of sector $S 15$ (on the left) progresses towards sector $S 14$.

- At $t=36.8 \mathrm{~ms}$, a "reacting appendix" is captured by the recirculation zone of the sector $S 15$.

- As it approaches the injector outlet, this flame surface grows and takes a closed (but wrinkled) shape $(t=37.8$ to $39.6 \mathrm{~ms})$.

- Meanwhile, the main front azimuthal progress is stopped, probably by lack of reactants which have been previously burnt by the isolated flame.

- After $t=40.4 \mathrm{~ms}$, the two fronts merge again and spread into the combustor volume towards the downstream and azimuthal directions. 
Compared to the other sectors ignitions, this flame isolation phenomenon is quite uncommon: in general, the main flame front is actually stretched but stays continuous while it passes through the main injector region.

To summarize, the flame propagation process is driven by two key phenomena:

- A thrust effect due to the thermal expansion of burnt gases. This effect depends rather on the mean reaction rate and the burnt gases outflux than on the flame leading point properties. It produces a continuous flame progress at a mean azimuthal speed of about $7.5 \mathrm{~m} . \mathrm{s}^{-1}$.

- A flame speed modulation by the aerodynamics. When the flame front is going through one sector of the combustor, the LP azimuthal speed is modulated by the own aerodynamics of the burner, i.e. the vortex breakdown due to the swirled injection. These speed fluctuations are of the order of $\pm 4 \mathrm{~m} . \mathrm{s}^{-1}$ and induce strong variations of the flame front curvature at the LP.

An interesting outcome of this analysis is that the flame propagation depends strongly on the balance between burnt gases leaving the chamber and burnt gases pushed azimuthally by expansion. This balance is controlled by the back pressure at the chamber outlet, suggesting that the overall ignition time decreases when less burnt gases are allowed to leave through the outlet.

In order to estimate the impact of the thickened flame model for LES (TFLES) on the flame propagation (see section "Combustion modeling"), three key modeling parameters are plotted on Fig. 22 versus azimuthal position of this point: the thickening factor $F$, the efficiency function $E$ and the mesh size at the leading point of the front. In the TFLES model [35], the thickening factor $F$ is adapted to the local cell size $\Delta x_{\text {cell }}$ in order to keep a constant 
number of nodes in the flame zone. This explains why $F$ variations along the LP path are strongly correlated to $\Delta x_{\text {cell }}$. As shown before, during the initial flame spreading, the LP is located in the downstream region of the combustor where the mesh is rather coarse. In this region, the thickening factor varies between 18 and 25. As the LP switches to the main injectors region, the mesh size falls down to $0.5<\Delta x_{\text {cell }}<1 \mathrm{~mm}$ leading to $5<F<10$. Focusing on the efficiency function $E$, values oscillate between 2 and 5 meaning that the turbulent reaction rate predicted by the TFLES model is twice to five times higher than the laminar value. Despite the very large size of the computational domain, thickening factors remain typically in the range 5 to 20 which are commonly used values for the TFLES model [55]. From the previous analysis, the flame progress is not directly driven by the local reaction rate but by the flow velocity and hot gas expansion. As a consequence, the TFLES model has only a moderate effect on the burner ignition process.

\section{Flame-spray interactions}

The previous section described the ignition mechanism in terms of flame topology, flow aerodynamics and total reaction rate. These properties depends on the chemical reaction as well as on two-phase flow effects such as droplet evaporation. Indeed, the fact that liquid fuel must vaporize before burning has an impact on the dynamics and structure of the flame. Figure 23 displays the time evolution of mean quantities in the sector $S 18$ (containing the igniter I1). Before reaction starts, a sufficient amount of fuel vapor in the flow is required. Due to the very low ambient temperature, the injected air-spray mixture is in saturated conditions so the initial gaseous equivalence ratio $\phi_{\text {gas }}^{0}$ 
is very low (see section "Configuration"). As a result, flammable conditions are only obtained after an initial evaporation phase $(t<9 \mathrm{~ms})$ thanks to the energy input by the hot igniter jets. These conditions are fulfilled at $t=9 \mathrm{~ms}$ allowing the reaction rate to grow faster and increase the spray evaporation. After the steady combustion regime is reached $(t>30 \mathrm{~ms})$, the reaction rate stays below the evaporation rate because all the fuel vapor cannot burn due to the rich global equivalence ratio $\left(\phi_{g}=1.5\right)$ These rich conditions also explain why the reaction rate starts to decrease at $t=17.4 \mathrm{~ms}$ while the equivalence ratio is still growing. From this instant, the reaction is limited by the oxidizer mass flux and produces unburnt gaseous fuel.

The effect of the liquid phase can also be highlighted thanks to a fuel mass fraction-temperature diagram at a given instant of the ignition sequence (Fig. 24). Compared to a single-phase distribution, all the gaseous fuel must be produced by evaporation and a saturation effect is observed: strong concentrations of vapor fuel cannot be found at temperatures close to the injection conditions $(T=273 K)$. Actually, most of the physical domain has a low $Y_{F}$ because the vaporized fuel is immediately consumed by the chemical reaction, as shown by the strong correlation between evaporation and reaction rates at the leading point (see Fig. 13b). Some significant fuel mass fractions are however observed at elevated temperatures (mainly above $1300 \mathrm{~K}$ ) corresponding to the unburnt gaseous fuel excess in hot gases. Figure 25 displays a scatter plot of heat release $\dot{\omega}_{T}$ and latent heat $\Pi$ as a function of temperature. The upper limit of $\dot{\omega}_{T}$ presents a typical shape for an Arrhenius law with a maximum heat release at high temperature. П corresponds to the heat lost by evaporation and is generally negligible compared to $\dot{\omega}_{T}$, except for dense-spray regions where high fuel vapor concentrations are produced (see Fig. 24). In these regions, 
the presence of liquid droplets may have a significant impact on the flame temperature. Elsewhere, the main effect of the spray is to introduce a time delay due to evaporation. According to Ballal and Lefebvre [64] and Myers and Lefebvre [65], this delay increases with the initial droplet size and has a slowing effect on the flame propagation speed. Indeed, tests in laminar configuration with similar unburnt conditions have shown that the spray induces a $20 \%$ decrease of the stoichiometric flame speed compared to the pure gaseous flame speed displayed on Fig. 2.

Finally, compared to gaseous mixtures, ignition of a saturated spray takes more time for two main reasons:

- an initial evaporation phase is required to produce a flammable mixture (in terms of equivalence ratio) from cold saturated conditions ;

- the flame progress is slower because of a lower propagation speed due to the evaporation delay.

\section{Flame stabilization times}

Another way to quantify the flame progress speed into the combustor is to look at ignition times for each single sector. Figure 26 displays the time variation of the total reaction rate in the five sectors of quadrant $Q 4$. All these sectors show a similar evolution: an initial growth phase up to a maximum reaction rate value, then a decreasing phase finally leading to a steady level (the same for all sectors). This steady regime corresponds to the flame stabilization in the burner. For each sector after $S 18$, the reaction rate rising phase starts shortly before the previous sector has reached its maximum. Until ignition of 
sector $S 16$, the total reaction rate in quadrant $Q 4$ presents a step-like evolution related to the successive ignition of sectors $S 18, S 17$ and $S 16$. This evolution is less consistent for the two last sectors, $S 15$ and $S 14$. The ignition time of sector $S i, t_{i g n}(S i)$, is defined as the instant where the total reaction rate in this sector is maximum (Fig. 26). Figure 27 compares $t_{i g n}$ with the rise of the mean temperature in each sector. Again, the temperature evolution is similar for all sectors, except $S 18$ that features an initial slow growing phase corresponding the heat input by the hot igniter jet $I 1$. One can notice that ignition occurs at a lower mean temperature when the flame is progressing from sector $S 18\left(\langle T\rangle_{S 18}=1675 K\right)$ to $S 14\left(\langle T\rangle_{S 14}=1040 \mathrm{~K}\right)$. Indeed, the flame progresses faster in the upstream region of the combustor than in the downstream one (see section "Flame topology"). As a result, the last burners are ignited upstream before the downstream flame has entered the sector. Lastly, Fig. 27 shows that the mean temperature over quadrant $Q 4$ has an almost linear increase from $t=12$ to $40 \mathrm{~ms}$.

$\Delta t_{i g n}(S i)$ is defined as the flame stabilization time delay between two successive sectors: $\Delta t_{i g n}(S i)=t_{i g n}(S i)-t_{i g n}\left(S i^{-}\right)$where $S i^{-}$is the preceding sector in the ignition sequence. Figure 28 compares $\Delta t_{i g n}$ for each sector (located by their azimuthal position) of the four quadrants. Ignition of the four burners surrounding the igniters (Phase II in "Introduction") lasts longer than the following ones. Moreover, these times change according to the azimuthal direction with respect to the igniter: around $17 \mathrm{~ms}$ for the clockwise-located sectors ( $S 9$ and $S 18)$ and around $23 \mathrm{~ms}$ for the two others ( $S 1$ and $S 10$ ). This $35 \%$ lag is due to the asymmetric cold flow induced by the swirled injection (see Fig. 18). Indeed, the analysis of the single sector flow has shown that the vortex breakdown is not symmetric because of its interactions with the six cold 
air jets coming from the internal and external holes (see Fig. 5). As a result, the vortex capturing the flame front before ignition (see Fig. 12, $t=10 \mathrm{~ms}$ ) is more intense in sectors $S 9$ and $S 18$ than in $S 1$ and $S 10$. Despite these initial variations, the four next sectors $\left(\theta_{i}=30 \mathrm{deg}\right.$. $)$ have the same ignition time $\Delta t_{i g n}(S i)=6 \mathrm{~ms}$. The ignition of sectors located at $30<\theta_{i}<90 \mathrm{deg}$. corresponds to Phase III. For quadrants $Q 2$ and $Q 4, \Delta t_{i g n}(S i)$ have a rather similar and constant value around $6 \mathrm{~ms}$. Ignition times for quadrants $Q 1$ and Q3 are larger and less consistent: they vary from 6 to $10 \mathrm{~ms}$. Again, the aerodynamics of the burner is invoked to explain these variations. The previous analyses have shown that the large eddies modulate the absolute flame speed. Accordingly, the randomness of these turbulent structures may explain the variations of the ignition time. Figure 29 provides another picture of the ignition times by plotting the time evolution of each flame leading point (LP) azimuthal position in each quadrant. In the initial phase $(t<12 \mathrm{~ms}$, Phase II), quadrants $Q 2$ and $Q 4$ are faster than $Q 1$ and $Q 3$, as previously noticed. From $t=12$ to $20 \mathrm{~ms}$ (Phase III), the four quadrants have rather similar evolutions. Indeed, the LP is located in the downstream region of the combustor (see Fig. 13d) so the flame progress is fairly independent of the swirled injection. On the contrary, from $t=20$ to $46 \mathrm{~ms}$, the LP of each quadrant has a different progress speed, quadrants $Q 1$ and $Q 3$ being slower than $Q 2$ and $Q 4$. During this period, the flame front evolves close to the injection (see Fig. 13d) where the flow aerodynamics generates flame speed fluctuations, as previously mentioned.

To summarize, three types of ignition times variations have been observed:

- A sector-to-sector variation due to the LP location in the axial direction.

- A quadrant-to-quadrant variation according to the azimuthal direction of 
the flame progress. This variation is due to the asymmetry of each single sector flow with respect to the corresponding injector axis.

- Both quadrants and sectors variations due to randomness of the turbulent resolved structures.

\section{Conclusion}

Thanks to massively parallel computing, LES is now able to simulate the ignition sequence of a full aeronautical combustor. The present calculation uses a compressible explicit solver, the Thickened Flame model with a simpified chemistry and Euler-Euler (EE) model to account for liquid fuel injection. This EE approach allows to keep a full parallel computing efficiency on a large unstructured grid (19 million cells) using 700 processors. To describe the major features of the flow inside the Turbomeca combustor, the computational domain includes the main air and fuel spray inlets, i.e. 18 main injectors and 108 primary holes while the 2 torch-igniters are modeled by hot jets. Simulating the full ignition of this 360 degrees annular chamber brings considerable new insight into the physics of such a complex phenomenon. Investigation of the results has been achieved thanks to various postprocessing analyses: two and three-dimensional views of the flame motion, Lagrangian tracking of the flame front leading point, Eulerian diagnostics in selected control sections and volumes, burnt gas mass balance and flame structure analysis. Several mechanisms have been identified as key factors of the ignition process:

- Having its own characteristic time, spray evaporation introduces a delay in the ignition time. Indeed, as the initial air-spray mixture is saturated, most of the liquid fuel has to be vaporized thanks to the heat released by 
combustion. This has an impact on the ignition of the first burners as well as on the consumption speed of the flame progressing from burner to burner.

- The unbalance between the burnt gases production in the flame and their outflux through the combustor outlet induces a mean flow in the azimuthal direction. As a result, the mean absolute flame speed is much higher than the actual turbulent flame consumption speed. This expansion effect is also responsible for the "jump" of the flame from a burner to its neighbour and seems necessary for fast propagation.

- The aerodynamics of the individual 18 burners strongly modulates the flame leading point speed according to whether the flame is entering or leaving the main injector recirculation zone. As this zone is not symmetrical, its effect on the front movement depends on the azimuthal direction of the flame progress.

In addition to these observations, a significant variability of the sectors and quadrants ignition times has been highlighted. These variations depends on the flame topology, its azimuthal direction of progress and the randomness of the large turbulent scales.

To conclude, LES shows a great potential to predict ignition into gas turbine combustors. As an unsteady approach, it is particularly adapted to such timevarying phenomena. Moreover, the flame propagation appears to be strongly influenced by the large turbulent structures which are explicitly resolved by the method. Computational costs can efficiently be handled thanks to massively parallel computing (The present simulation took less than a week of execution time). For the sake of predictive calculations, further developments are required. Among them are: to account for spray polydispersion, to include more realistic evaporation and chemistry models for kerosene, to describe more 
accurately the true combustor inflows (full swirler geometry, cooling films, multi-perforated walls, etc.) and to analyse the impact of the outflow condition. Such computations will also have to be repeated in simpler academic configurations for which experimental results are available (see for example Ahmed et al. [66]). These comparisons will be useful to fully validate all submodels.

\section{Acknowledgements}

The authors want to thank CRAY Inc. and CEA-DAM for providing computational ressources. Turbomeca (Safran group) is also gratefully acknowledged for its support.

\section{References}

[1] Lefebvre, A.H., Gas Turbines Combustion, Taylor \& Francis, 1999.

[2] D. Ballal, A. Lefebvre, The influence of flow parameters on minimum ignition energy and quenching distance, Proc. Combust. Inst. 15 (1974) 1473-1481.

[3] M. Champion, B. Deshaies, G. Joulin, K. Kinoshita, Spherical flame initiation: Theory versus experiments for lean propane-air mixtures, Combust. Flame 65 (1986) 319-337.

[4] T. Sloane, Energy requirements for spherical ignitions in methane-air mixtures at different equivalence ratios, Combust. Sci. Tech. 73 (1990) 351-365.

[5] J. Beduneau, B. Kim, L. Zimmer, Y. Ikeda, Measurements of minimum ignition energy in premixed laminar methane/air flow by using laser induced spark, Combust. Flame 132 (4) (2003) 653-665. 
[6] V. Kurdyumov, J. Blasco, A. Sanchez, A. Linan, On the calculation of the minimum ignition energy, Combust. Flame 136 (3) (2004) 394-397.

[7] A. Alkidas, P. Durbetaki, Ignition characteristics of a stagnation point combustible mixture, Combust. Sci. Tech. 3 (4) (1971) 187-194.

[8] M. Baum, T. Poinsot, Effects of mean flow on premixed flame ignition, Combust. Sci. Tech. 106 (1) (1995) 19-39.

[9] Y. Ko, V. Arpaci, Spark ignition of propane-air mixtures near the minimum ignition energy: Part II. A model development, Combust. Flame 83 (1991) 88105.

[10] T. Sloane, P. Ronney, A comparison of ignition phenomena with detailed and simplified kinetics, Combust. Sci. Tech. 88 (1992) 1-13.

[11] T. Sloane, Ignition and flame propagation modeling with an improved propane oxidation mechanism, Combust. Sci. Tech. 83 (1992) 77-96.

[12] T. Sloane, Numerical simulation of electric spark ignition in methane-air mixtures at pressures above one atmosphere, Combust. Sci. Tech. 86 (1992) $121-133$.

[13] S. Ahmed, E. Mastorakos, Spark ignition of lifted turbulent jet flames, Combust. Flame 146 (1-2) (2006) 215-231.

[14] R. Maly, Ignition model for spark discharges and the early phase of flame front growth, Proc. Combust. Inst. 18 (1981) 1747-1754.

[15] S. Pischinger, J. Heywood, A model for flame kernel development in a sparkignition engine, Proc. Combust. Inst. 23 (1990) 1033-1040.

[16] P. Boudier, S. Henriot, T. Poinsot, T. Baritaud, A model for turbulent flame ignition and propagation in spark ignition engines, Proc. Combust. Inst. 24 (1992) 503-510. 
[17] T. Kravchik, E. Sher, Numerical modeling of spark ignition and flame initiation in a quiescent methane-air mixture, Combust. Flame 99 (1994) 635-643.

[18] S. Richard, O. Colin, O. Vermorel, A. Benkenida, C. Angelberger, D. Veynante, Towards large eddy simulation of combustion in spark ignition engines, Proc. Combust. Inst. 31 (2007) 3059-3066.

[19] L. Selle, G. Lartigue, T. Poinsot, R. Koch, K.-U. Schildmacher, W. Krebs, B. Prade, P. Kaufmann, D. Veynante, Compressible large-eddy simulation of turbulent combustion in complex geometry on unstructured meshes, Combust. Flame 137 (4) (2004) 489-505.

[20] T. Poinsot, D. Veynante, Theoretical and numerical combustion, 2nd Edition, R.T. Edwards, Inc., 2005.

[21] H. Pitsch, Large eddy simulation of turbulent combustion, Ann. Rev. Fluid Mech. 38 (2006) 453-482.

[22] S. Menon, P. N., Subgrid modeling for simulation of spray combustion in large scale combustors, AIAA Journal 44 (709-723).

[23] H. El-Asrag, S. Menon, Large eddy simulation of bluff-body stabilized swirling non-premixed flames, Proc. Combust. Inst. 31 (2007) 1747-1754.

[24] M. Freitag, J. Janicka, Investigation of a strongly swirled premixed flame using LES, Proc. Combust. Inst. 31 (2007) 1477-1485.

[25] Y. Sommerer, D. Galley, T. Poinsot, S. Ducruix, F. Lacas, D. Veynante, Large eddy simulation and experimental study of flashback and blow-off in a lean partially premixed swirled burner, J. Turb. 5 (37) (2004) 1-21.

[26] M. Boileau, S. Pascaud, E. Riber, B. Cuenot, L. Gicquel, T. Poinsot, M. Cazalens, Investigation of two-fluid methods for Large Eddy Simulation of spray combustion in gas turbines, Flow, Turb. and Combustion, in press. 
[27] J. Schluter, S. Apte, G. Kalitzin, E. vdWeide, J. Alonso, H. Pitsch, Large-scale integrated LES-RANS simulations of a gas turbine engine, in: Annual Research Briefs, Center for Turbulence Research, NASA Ames/Stanford Univ., 2005, pp. $111-121$.

[28] T. Schönfeld, M. Rudgyard, Steady and unsteady flows simulations using the hybrid flow solver AVBP, AIAA Journal 37 (11) (1999) 1378-1385.

[29] O. Colin, M. Rudgyard, Development of high-order taylor-galerkin schemes for unsteady calculations, J. Comput. Phys. 162 (2) (2000) 338-371.

[30] V. Moureau, G. Lartigue, Y. Sommerer, C. Angelberger, O. Colin, T. Poinsot, High-order methods for DNS and LES of compressible multi-component reacting flows on fixed and moving grids, J. Comput. Phys. 202 (2) (2005) $710-736$.

[31] M. Moreau, B. Bedat, O. Simonin, From Euler-Lagrange to Euler-Euler large eddy simulation approaches for gas-particle turbulent flows, in: A. FED (Ed.), ASME Fluids Engineering Summer Conference, 2005.

[32] E. Riber, M. Garcia., V. Moureau, H. Pitsch, O. Simonin, T. Poinsot, Evaluation of numerical strategies for LES of two-phase reacting flows, in: Proc. of the Summer Program, Center for Turbulence Research, NASA Ames/Stanford Univ., 2006, pp. 197-213.

[33] A. Sengissen, A. Giauque, G. Staffelbach, M. Porta, W. Krebs, P. Kaufmann, T. Poinsot, Large eddy simulation of piloting effects on turbulent swirling flames, Proc. Combust. Inst. 31 (2007) 1729-1736.

[34] A. Sengissen, J. F. VanKampen, R. Huls, G. Stoffels, J. B. W. Kok, T. Poinsot, LES and experimental studies of cold and reacting flows in a swirled partially premixed burner with and without fuel modulation, Combust. Flame 150 (2007) $40-53$. 
[35] P. Schmitt, T. Poinsot, B. Schuermans, K. Geigle, Large-eddy simulation and experimental study of heat transfer, nitric oxide emissions and combustion instability in a swirled turbulent high pressure burner, J. Fluid Mech. 570 (2007) $17-46$.

[36] T. Schönfeld, M. Rudgyard, A cell-vertex approach to local mesh refinement for the 3-D Euler equations, in: AIAA (Ed.), 32nd AIAA Aerospace Sciences Meeting \& Exhibit, Reno, NV, 1994.

[37] F. Nicoud, F. Ducros, Subgrid-scale stress modelling based on the square of the velocity gradient, Flow Turb. and Combustion 62 (3) (1999) 183-200.

[38] T. Poinsot, S. Lele, Boundary conditions for direct simulations of compressible viscous flows, J. Comput. Phys. 101 (1) (1992) 104-129.

[39] D. Caraeni, C. Bergstrom, L. Fuchs, Modeling of liquid fuel injection, evaporation and mixing in a gas turbine burner using large eddy simulation, Flow Turb. and Combustion 65 (2000) 223-244.

[40] F. Ham, S. V. Apte, G. Iaccarino, X. Wu, M. Herrmann, G. Constantinescu, K. Mahesh, P. Moin, Unstructured LES of reacting multiphase flows in realistic gas turbine combustors, in: Annual Research Briefs - Center for Turbulence Research, NASA Ames/Stanford Univ., 2003, pp. 139-160.

[41] K. Mahesh, G. Constantinescu, S. Apte, G. Iaccarino, F. Ham, P. Moin, Progress towards large-eddy simulation of turbulent reacting and non-reacting flows in complex geometries, in: Annual Research Briefs, Center for Turbulence Research, NASA Ames/Stanford Univ., 2002, pp. 115-142.

[42] K. Mahesh, G. Constantinescu, S. Apte, G. Iaccarino, F. Ham, P. Moin, Large eddy simulation of reacting turbulent flows in complex geometries, in: ASME J. Appl. Mech., Vol. 73, 2006, pp. 374-381. 
[43] P. Moin, S. V. Apte, Large-eddy simulation of realistic gas turbine combustors, AIAA Journal 44 (4) (2006) 698-708.

[44] V. Sankaran, S. Menon, LES of spray combustion in swirling flows, J. Turb. 3 (2002) 011.

[45] P. Moin, Large eddy simulation of multi-phase turbulent flows in realistic combustors, Prog. Comput. Fluid Dynamics 4 (2004) 237-240.

[46] A. Kaufmann, Vers la simulation des grandes échelles en formulation Euler/Euler des écoulements réactifs diphasiques, Ph.D. thesis, INP Toulouse (2004).

[47] J.-B. Mossa, Extension polydisperse pour la description Euler-Euler des écoulements diphasiques réactifs, Ph.D. thesis, INP Toulouse (2005).

[48] E. Riber, Développement de la méthode de simulation aux grandes échelles pour les écoulements diphasiques turbulents, Ph.D. thesis, INP Toulouse (2007).

[49] P. Février, O. Simonin, K. Squires, Partitioning of particle velocities in gas-solid turbulent flows into a continuous field and a spatially uncorrelated random distribution: Theoretical formalism and numerical study, J. Fluid Mech. 533 (2005) 1-46.

[50] E. Riber, M. Moreau, O. Simonin, B. Cuenot, Towards large eddy simulation of non-homogeneous particle laden turbulent gas flows using Euler-Euler approach, in: 11th Workshop on Two-Phase Flow Predictions, Merseburg, Germany, 2005.

[51] A. Kaufmann, O. Simonin, T. Poinsot, J. Helie, Dynamics and dispersion in Eulerian-Eulerian DNS of two-phase flow, in: Proc. of the Summer Program, Center for Turbulence Research, NASA AMES/Stanford University, USA, 2002, pp. 381-391.

[52] E. Riber, M. Moreau, O. Simonin, B. Cuenot, Development of Euler-Euler 
LES approach for gas-particle turbulent jet flow, in: ASME - European Fluids Enigneering Summer Meeting, Miami, Florida - USA, 2006.

[53] S. Li, B. Varatharajan, F. Williams, Chemistry of JP-10 ignition, AIAA Journal 39 (12) (2001) 2351-2356.

[54] L. Vervisch, B. Labegorre, J. Réveillon, Hydrogen-sulphur oxy-flames analysis and single-step flame tabulated chemistry, Fuel 83 (4-5) (2004) 605-614.

[55] O. Colin, F. Ducros, D. Veynante, T. Poinsot, A thickened flame model for large eddy simulations of turbulent premixed combustion, Phys. Fluids 12 (7) (2000) $1843-1863$.

[56] C. Angelberger, F. Egolfopoulos, D. Veynante, Large eddy simulations of chemical and acoustic effects on combustion instabilities, Flow Turb. and Combustion 65 (2) (2000) 205-22.

[57] C. Martin, L. Benoit, F. Nicoud, T. Poinsot, Analysis of acoustic energy and modes in a turbulent swirled combustor, in: Proc. of the Summer Program, Center for Turbulence Research, NASA Ames/Stanford Univ., Stanford, 2004, pp. $377-394$.

[58] G. Staffelbach, L. Gicquel, T. Poinsot, Highly parallel large eddy simulations of multiburner configurations in industrial gas turbines, Lecture Notes in Computational Science and Engineering - Complex effects in Large Eddy Simulations 56 (2006) 326-336.

[59] G. Staffelbach, T. Poinsot, High performance computing for combustion applications, in: Super Computing 2006, Tampa, Florida, USA, 2006.

[60] G. Staffelbach, Simulation aux grandes échelles des instabilités de combustion dans les configurations multi-brûleurs, Ph.D. thesis, INP Toulouse (2006).

[61] M. Boileau, J.-B. Mossa, B. Cuenot, T. Poinsot, D. Bissières, C. Bérat, Toward 
LES of an ignition sequence in a full helicopter combustor, in: 1st Workshop INCA, SNECMA, Villaroche, France, 2005, pp. 27-34.

[62] D. Dowdy, D. Smith, S. Taylor, The use of expanding spherical flames to determine burning velocities and stretch effects in hydrogen/air mixtures, Proc. Combust. Inst. 23 (1990) 325-332.

[63] P. Boston, D. Bradley, F. Lung, I. Wince, F. Weinberg, Flame initiation in lean, quiescent and turbulent mixtures with various igniters, Proc. Combust. Inst. 20 (1984) 141-149.

[64] D. R. Ballal, A. H. Lefebvre, Flame propagation in heterogeneous mixtures of fuel droplets, fuel vapor and air, Proc. Combust. Inst. 18 (1981) 321-327.

[65] G. Myers, A. Lefebvre, Flame propagation in heterogeneous mixtures of fuel drops and air, Combust. Flame 66 (1986) 193-210.

[66] Ahmed, SF and Balachandran, R. and Marchione, T. and Mastorakos, E., Spark ignition of turbulent nonpremixed bluff-body flames, Combust. Flame 151 (1-2) (2007) 366-385. 


\begin{tabular}{l|l}
\multicolumn{1}{c}{ Name (Fig. 5) } & \multicolumn{1}{c}{ Physical parameters } \\
\hline Primary holes (108) & Flat velocity profile \\
& $\dot{m}_{\text {air }}=41.4 \mathrm{~g} \cdot \mathrm{s}^{-1}$ \\
& $T_{\text {air }}=273 \mathrm{~K}$ \\
\hline Main injectors (18) & \\
Air inlet & Velocity profile (see Fig. 6) \\
& $\dot{m}_{\text {air }}=46.08 \mathrm{~g} \cdot \mathrm{s}^{-1}$ \\
& $T_{\text {air }}=273 \mathrm{~K}$ \\
Kerosene spray & Mass flux profile (see Fig. 6) \\
& $\dot{m}_{\text {fuel }}=9.30 \mathrm{~g} \cdot \mathrm{s}^{-1}$ \\
& $T_{\text {fuel }}=273 \mathrm{~K}$ \\
& $d=25 \mu \mathrm{m}$ (monodisperse) \\
\hline Hot igniter jets (2) & $\phi_{g}=1.5$ \\
Burnt gas mixture & $\dot{m}_{\text {jet }}=1.24 \mathrm{~g} . \mathrm{s}^{-1}$ \\
\hline Combustor walls & $T_{\text {jet }}=2369 \mathrm{~K}$ \\
\hline Outlet & No slip, adiabatic \\
\hline
\end{tabular}

Table 1

Physical parameters values for the boundary conditions. 


\section{List of Figures}

1 Number of particles $N_{d}$ as a function of the processor number.

2 Adiabatic flame temperature $T_{2}$ and laminar flame speed $S_{L}$ as a function of equivalence ratio $\phi$ for the one-step chemistry compared with the reference detailed chemistry [53].

3 Speed-up of the LES code on the Rochester (US) IBM BlueGene/L as a function of number of processors

4 Global view of the VESTA combustor featuring 14 of the 18 sectors.

5 Single sector representing $1 / 18^{\text {th }}$ of the full computing domain and featuring half an ignition jet.

$6 \quad$ Main injector boundary conditions: axial velocity $\left(U_{x}\right)$, radial velocity $\left(U_{r}\right)$, azimuthal velocity $\left(U_{\theta}\right)$ and axial fuel spray mass flux $\left(F_{l i q}\right)$.

7 Real configuration (a.) and calculated configuration (b.).

8 Sketch of the annular combustor showing the positions of the two igniters ( $I 1$ and $I 2$ ), the eighteen sectors ( $S 1$ to $S 18$ ), the four quadrants $(Q 1$ to $Q 4)$ and their four corresponding azimuthal angles $\left(\theta_{1}\right.$ to $\left.\theta_{4}\right) \cdot \theta_{4}=50$ and $70 \mathrm{deg}$. are the position of two analysis sections. 
$93 \mathrm{D}$ view of the computational domain showing the two igniters $I 1$ and $I 2$, the cutting surface $C$ and the surface $C_{d e v}$ obtained by developing $C$.

10 Two successive instants $(t=14$ and $19.2 \mathrm{~ms})$ of the ignition sequence: surface $C$ colored by axial velocity (light blue: $-20 \mathrm{~m} . \mathrm{s}^{-1} \rightarrow$ yellow: $+20 \mathrm{~m} \cdot \mathrm{s}^{-1}$ ), iso-surface of velocity $U=38 \mathrm{~m} . \mathrm{s}^{-1}$ colored by temperature (turquoise blue: $273 K \rightarrow$ red: $2400 K$ ) and iso-surface of progress rate $\mathcal{Q}=200$ mol.s ${ }^{-1}$ (shiny light blue) representing the flame front. The two high-speed hot jets used for ignition appear as red zones in the pictures (marked I1 and I2).

11 Two successive instants $(t=29.2$ and $46 \mathrm{~ms})$ of the ignition sequence: surface $C$ colored by axial velocity (light blue: $-20 \mathrm{~m} . \mathrm{s}^{-1} \rightarrow$ yellow: $\left.+20 \mathrm{~m} . \mathrm{s}^{-1}\right)$, iso-surface of velocity $U=38 \mathrm{~m} . \mathrm{s}^{-1}$ colored by temperature (turquoise blue: $273 K \rightarrow$ red: $2400 K$ ) and iso-surface of progress rate $\mathcal{Q}=200$ mol.s ${ }^{-1}$ (shiny light blue) representing the flame front. The two high-speed hot jets used for ignition appear as red zones in the pictures (marked I1 and I2).

12 Surface $C_{d e v}$ (see Fig. 9) colored by temperature at successive instants of the ignition sequence. Black lines: reaction rate iso-lines. 
13 View along the $C_{\text {dev }}$ plane (bordered by the thick line) of the flame front leading point (LP) trajectory through sectors $S 18$ to $S 14$ (d.). $s_{4}$ is the azimuthal curvilinear abscissa defined as $s_{4}=R \theta_{4}$ where $R$ is the radial position of the main injectors axis. The three upper graphs show various properties of the LP as a function of $s_{4}$ : flow azimuthal velocity $U_{\theta, L P}$ (a.), azimuthal LP speed $V_{L P}$ (a. and c.), fuel evaporation rate $\Gamma$ (b.), fuel reaction rate $\dot{\omega}_{F}$ (b.) and gaseous equivalence ratio $\phi_{L P}$ (c.).

14 Axial view of the flame leading point trajectory between $7 \mathrm{~ms}$ and $36.4 \mathrm{~ms} . \theta_{4}=50$ and $70 \mathrm{deg}$. are the positions of the two control surfaces used in Fig. 15.

15 Time evolution of the flow azimuthal velocity $\langle U\rangle_{\theta}$ (lines) and temperature $\langle T\rangle_{\theta}$ (lines with circles) averaged over an iso- $\theta_{4}$ section for $\theta_{4}=50$ and $70 \mathrm{deg}$. (see Fig. 14).

16 Time evolution of the products mass balance: temporal variation of the total mass of products $\dot{m}_{p}$, total products reaction rate $\dot{m}_{c o m b}$, mass fluxes through the outlet $\dot{m}_{\text {out }}$ and through the hot igniter jets inlets $\dot{m}_{H J}$.

17 Comparison between the mean absolute front speed $V_{F}$, the mean leading point azimuthal speed among the four quadrant $\left\langle V_{L P}\right\rangle_{Q}$ and the mean consumption speed $\left\langle S_{c}\right\rangle$ (multiplied by $5)$. 
18 Time-averaged stream lines in surface $C$ obtained with a single-sector cold-flow calculation.

19 Three-step evolution of the flame front (thick grey lines) when crossing the main swirled jet.

20 Radial view of the flame front progress from sector $S 16$ to $S 15$ through 5 successive snapshots (A-C') of the iso-surface of temperature $T=1500 K$ (a.). Mean fuel reaction rate $\left\langle\dot{\omega}_{F}\right\rangle_{S i}$ in sectors $S 15$ and $S 16$ (b.), leading point (LP) azimuthal speed $V_{L P}$ and flame front curvature at LP $\gamma_{L P}$ (c.) as a function of the azimuthal curvilinear abscissa of the LP $s_{4}$.

21 Progress of the flame front (iso-surface of $T=1500 \mathrm{~K}$ ) from sector $S 15$ to sector $S 14$.

22 Thickening factor $F$, efficiency function $E$ and computational cell size $\Delta x_{c e l l}$ as a function of the flame leading point azimuthal position in quadrant $Q_{4}$ (see Fig. 8).

23 Temporal evolution of mean quantities in sector $S 18$ : evaporation rate $\langle\Gamma\rangle_{S 18}$, fuel reaction rate $\left\langle\dot{\omega}_{F}\right\rangle_{S 18}$ and gaseous equivalence ratio $\left\langle\phi_{\text {gas }}\right\rangle_{S 18}$.

24 Scatter plot of gaseous fuel mass fraction versus temperature at $t=28 \mathrm{~ms}$.

25 Scatter plot of heat release $\dot{\omega}_{T}$ and latent heat $\Pi$ versus temperature at $t=28 \mathrm{~ms}$. 
26 Time evolution of the total fuel reaction rate into the $Q 4$ quadrant and each single sector of $Q 4$.

27 Time evolution of the mean temperature into the $Q 4$ quadrant and each single sector of $Q 4$.

28 Flame stabilization time delay between two successive sectors in the four quadrants as a function of the azimuthal sector angle with respect to the igniter (I1 or $I 2)$.

29 Time evolution of the azimuthal position of the flame front leading point $\theta_{i}$ in each of the four $Q i$ quadrants. 


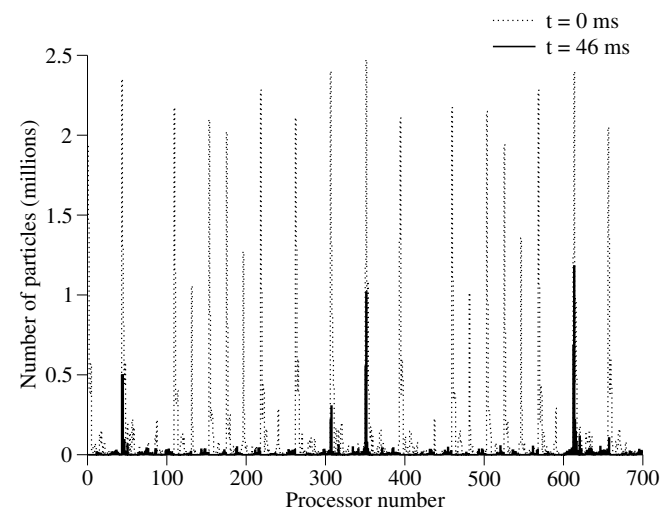

Fig. 1. Number of particles $N_{d}$ as a function of the processor number.

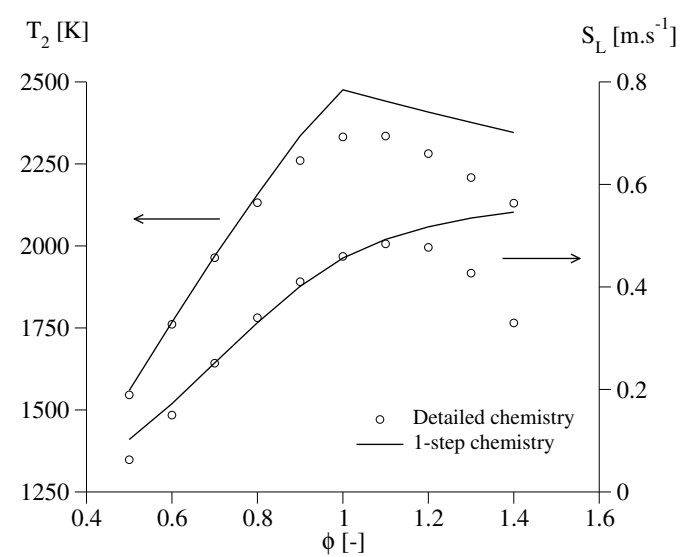

Fig. 2. Adiabatic flame temperature $T_{2}$ and laminar flame speed $S_{L}$ as a function of equivalence ratio $\phi$ for the one-step chemistry compared with the reference detailed chemistry [53]. 


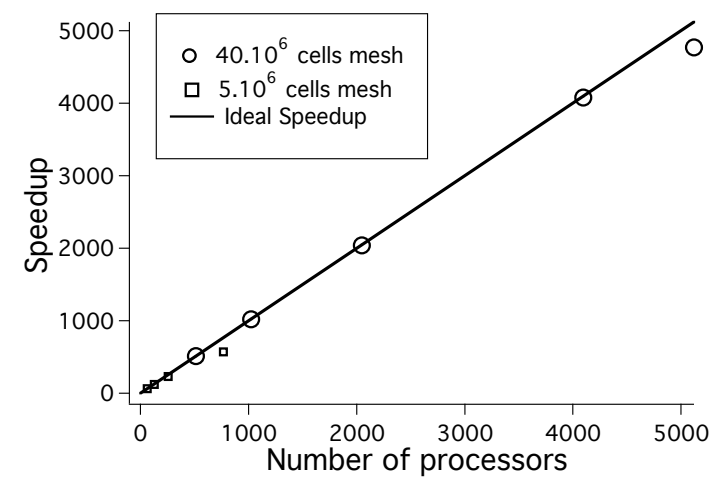

Fig. 3. Speed-up of the LES code on the Rochester (US) IBM BlueGene/L as a function of number of processors 


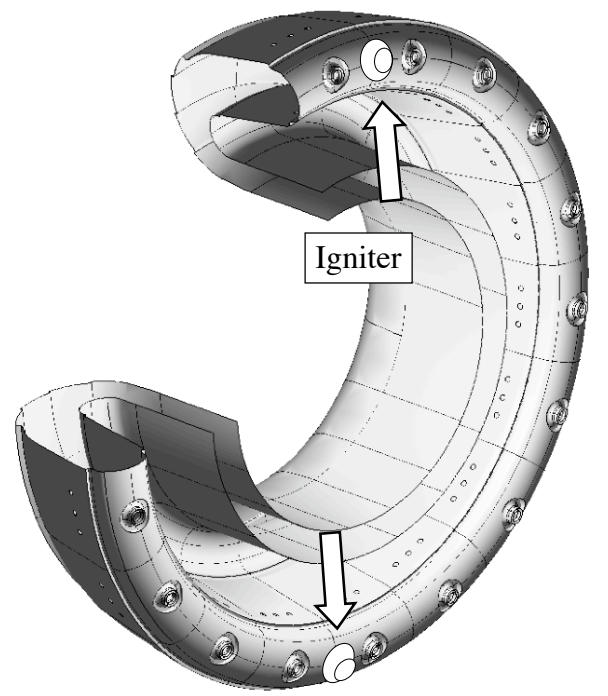

Fig. 4. Global view of the VESTA combustor featuring 14 of the 18 sectors.

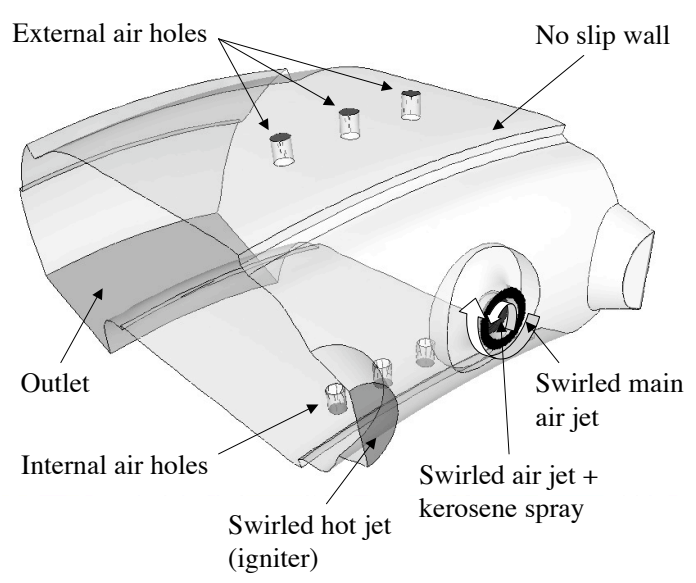

Fig. 5. Single sector representing $1 / 18^{\text {th }}$ of the full computing domain and featuring half an ignition jet. 


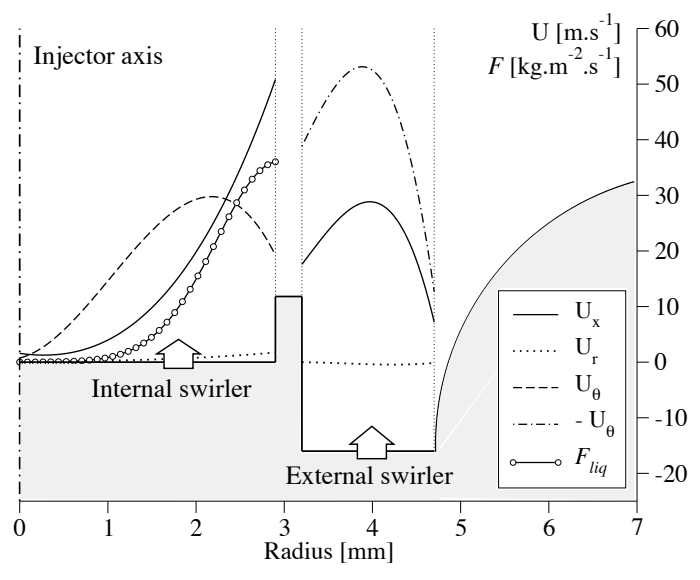

Fig. 6. Main injector boundary conditions: axial velocity $\left(U_{x}\right)$, radial velocity $\left(U_{r}\right)$, azimuthal velocity $\left(U_{\theta}\right)$ and axial fuel spray mass flux $\left(F_{l i q}\right)$.

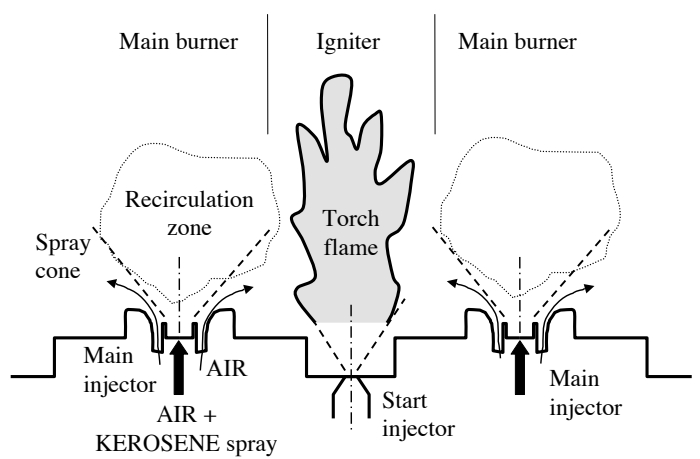

a.

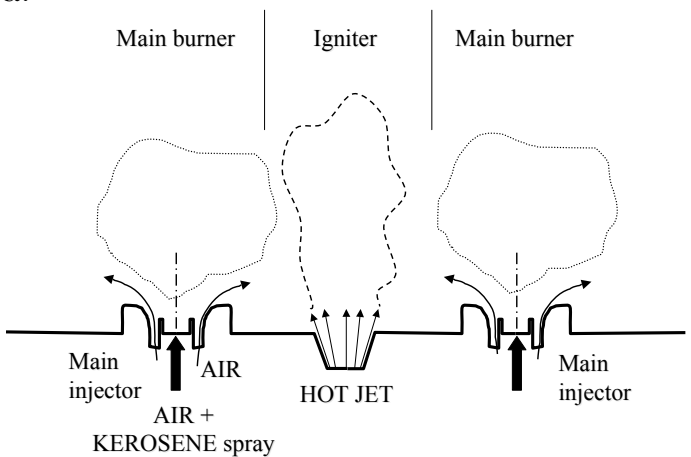

b.

Fig. 7. Real configuration (a.) and calculated configuration (b.). 


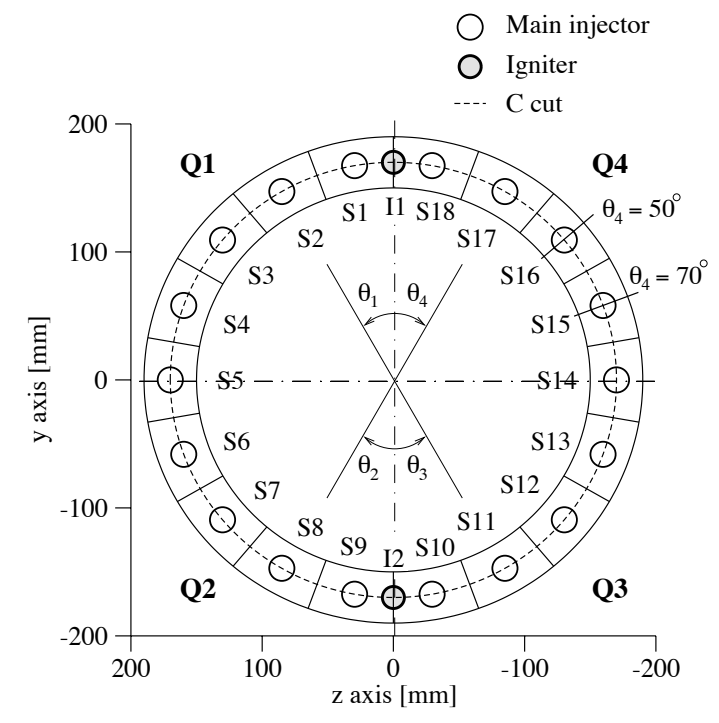

Fig. 8. Sketch of the annular combustor showing the positions of the two igniters (I1 and $I 2$ ), the eighteen sectors ( $S 1$ to $S 18)$, the four quadrants ( $Q 1$ to $Q 4$ ) and their four corresponding azimuthal angles $\left(\theta_{1}\right.$ to $\left.\theta_{4}\right) . \theta_{4}=50$ and $70 \mathrm{deg}$. are the position of two analysis sections.

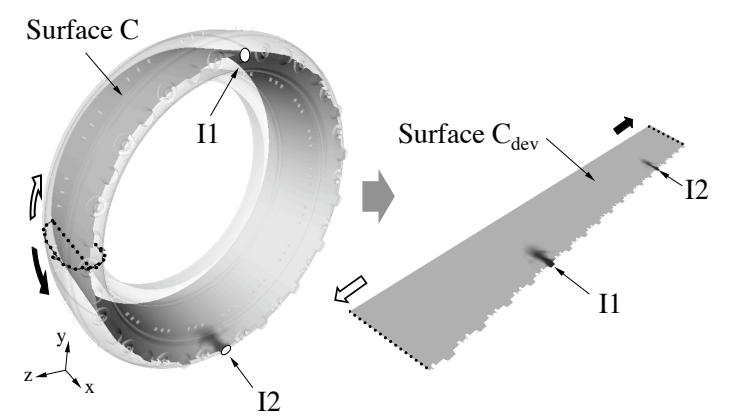

Fig. 9. $3 \mathrm{D}$ view of the computational domain showing the two igniters $I 1$ and $I 2$, the cutting surface $C$ and the surface $C_{d e v}$ obtained by developing $C$. 

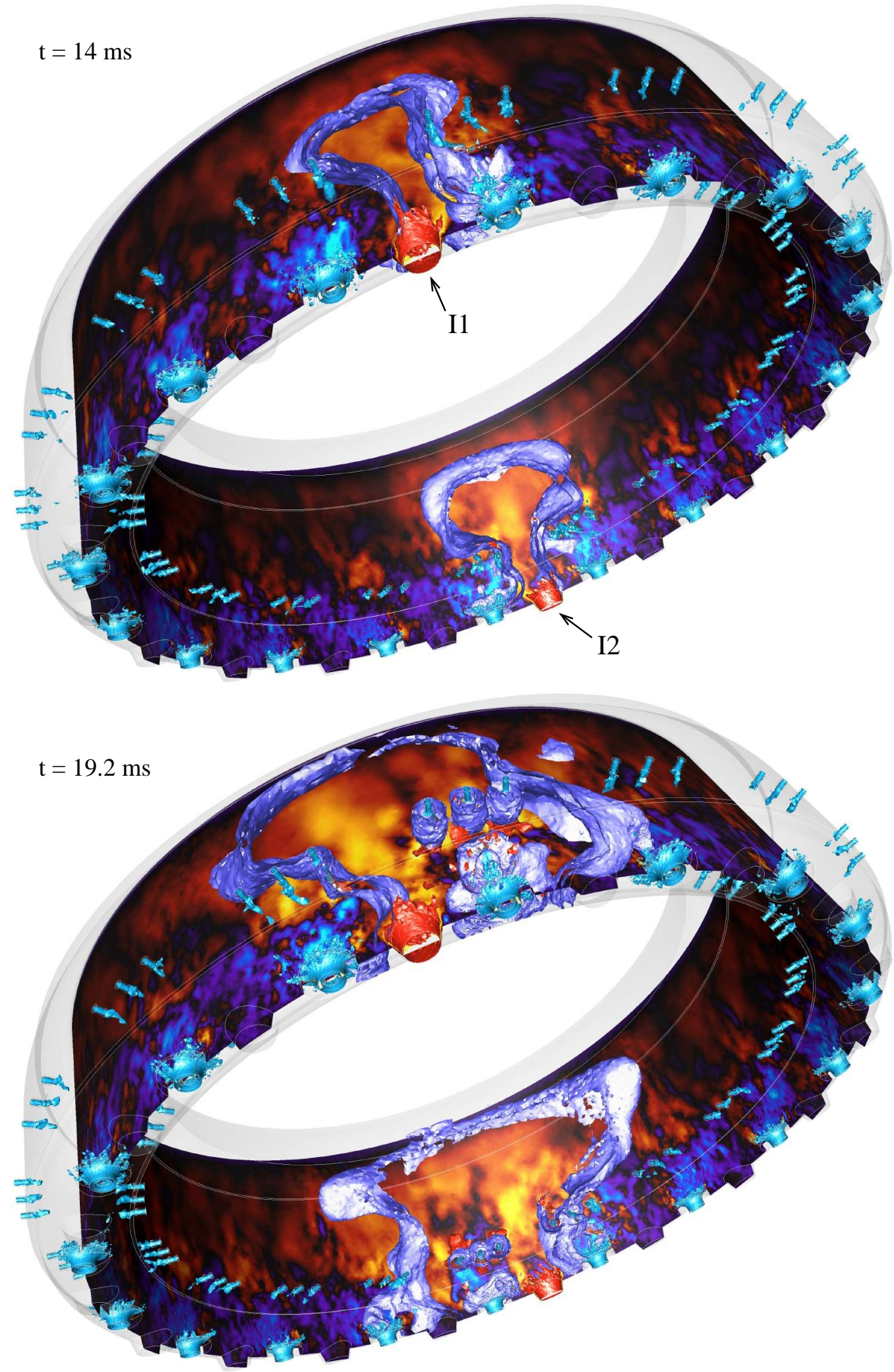

Fig. 10. Two successive instants $(t=14$ and $19.2 \mathrm{~ms})$ of the ignition sequence: surface $C$ colored by axial velocity (light blue: $-20 \mathrm{~m} . \mathrm{s}^{-1} \rightarrow$ yellow: $+20 \mathrm{~m} . \mathrm{s}^{-1}$ ), isosurface of velocity $U=38 \mathrm{~m} . \mathrm{s}^{-1}$ colored by temperature (turquoise blue: $273 \mathrm{~K} \rightarrow$ red: $2400 \mathrm{~K}$ ) and iso-surface of progress rate $\mathcal{Q}=200 \mathrm{~mol}^{-1}$ (shiny light blue) representing the flame front. The two high-speed hot jets used for ignition appear as red zones in the pictures (marked I1 and I2). 

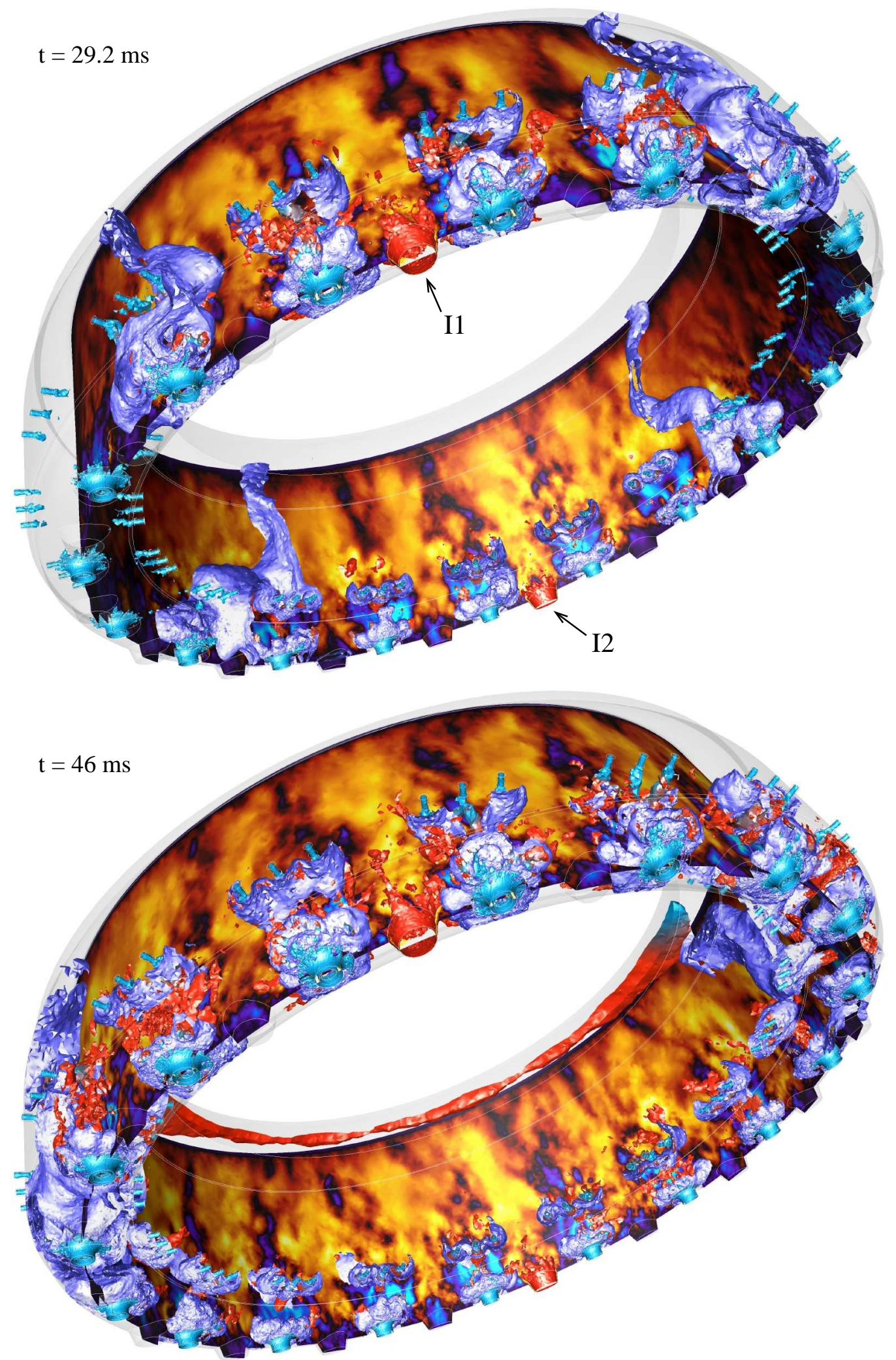

Fig. 11. Two successive instants $(t=29.2$ and $46 \mathrm{~ms})$ of the ignition sequence: surface $C$ colored by axial velocity (light blue: $-20 \mathrm{~m} . \mathrm{s}^{-1} \rightarrow$ yellow: $+20 \mathrm{~m} . \mathrm{s}^{-1}$ ), isosurface of velocity $U=38 \mathrm{~m} . \mathrm{s}^{-1}$ colored by temperature (turquoise blue: $273 \mathrm{~K} \rightarrow$ red: $2400 \mathrm{~K}$ ) and iso-surface of progress rate $\mathcal{Q}=200 \mathrm{~mol}^{-1}$ (shiny light blue) representing the flame front. The two high-speed hot jets used for ignition appear as red zones in the pictures (marked I1 and I2). 


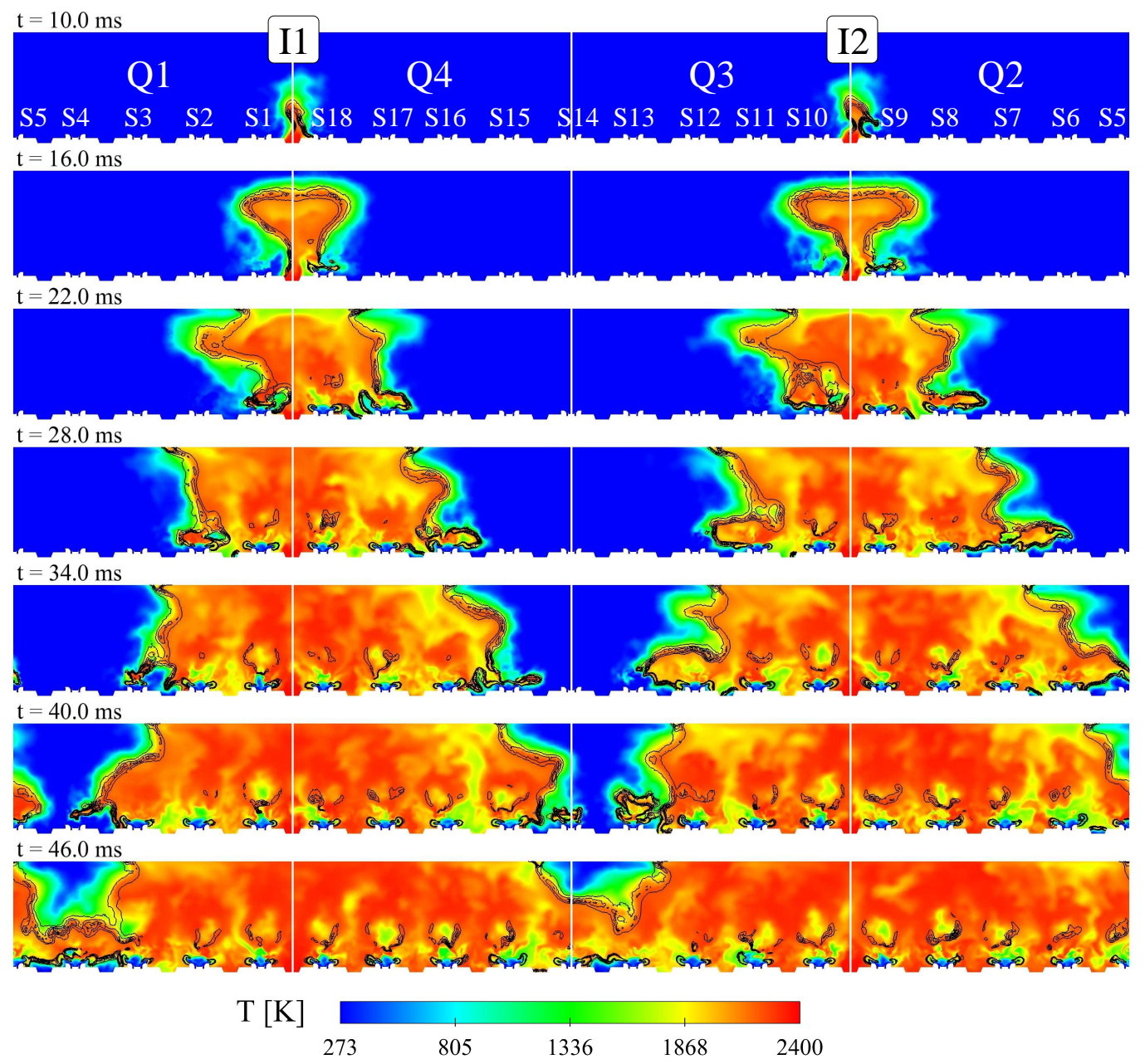

Fig. 12. Surface $C_{d e v}$ (see Fig. 9) colored by temperature at successive instants of the ignition sequence. Black lines: reaction rate iso-lines. 


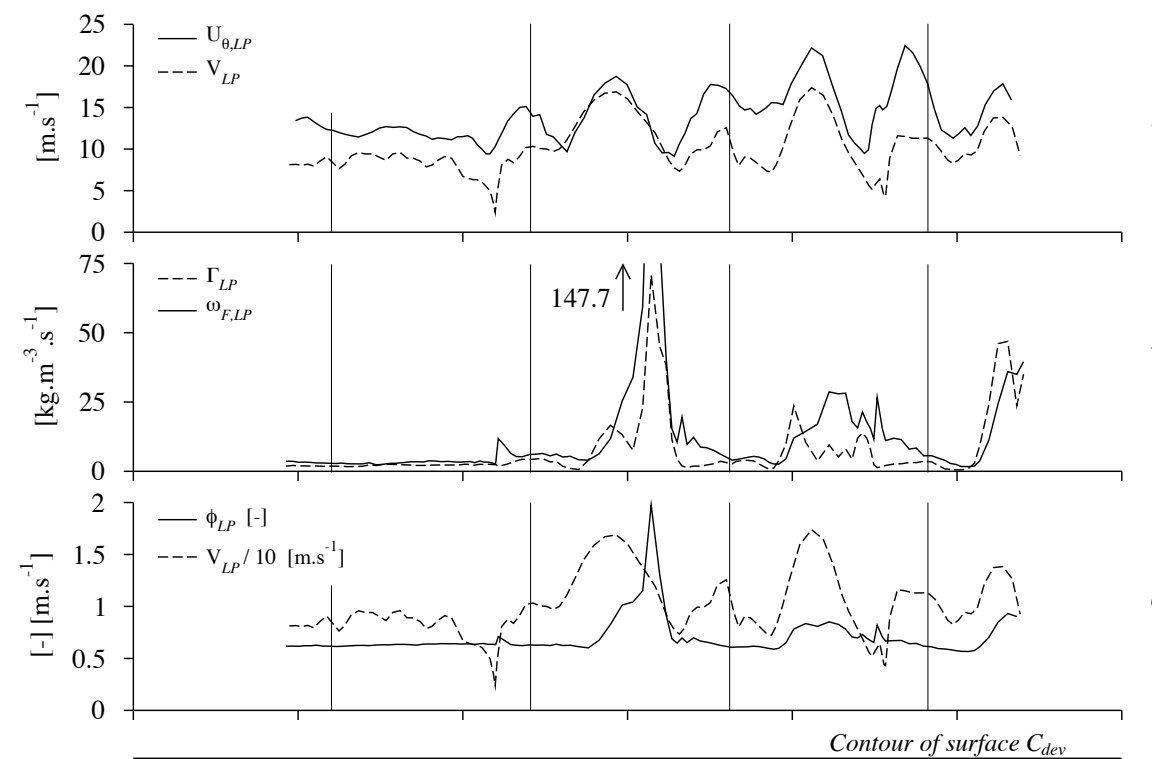

b.

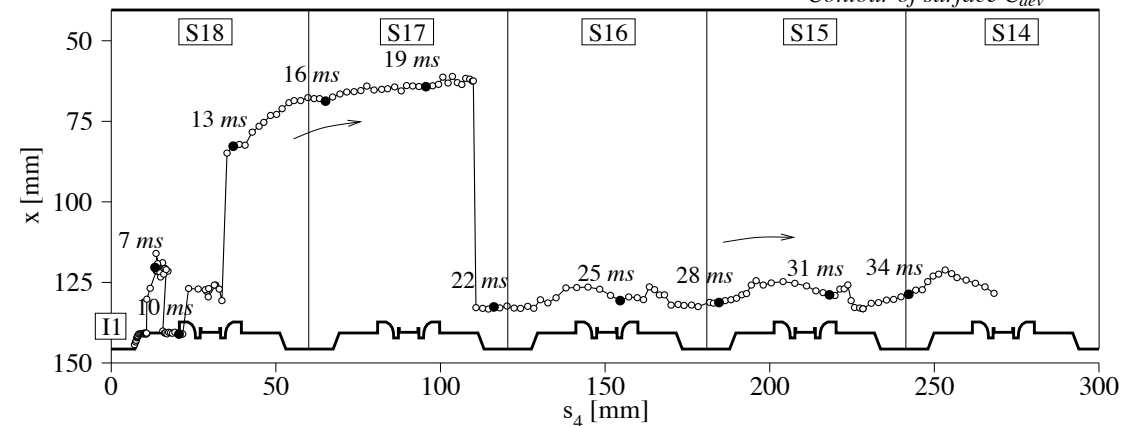

Fig. 13. View along the $C_{\text {dev }}$ plane (bordered by the thick line) of the flame front leading point (LP) trajectory through sectors $S 18$ to $S 14$ (d.). $s_{4}$ is the azimuthal curvilinear abscissa defined as $s_{4}=R \theta_{4}$ where $R$ is the radial position of the main injectors axis. The three upper graphs show various properties of the LP as a function of $s_{4}$ : flow azimuthal velocity $U_{\theta, L P}$ (a.), azimuthal LP speed $V_{L P}$ (a. and c.), fuel evaporation rate $\Gamma$ (b.), fuel reaction rate $\dot{\omega}_{F}$ (b.) and gaseous equivalence ratio $\phi_{L P}(\mathrm{c})$. 


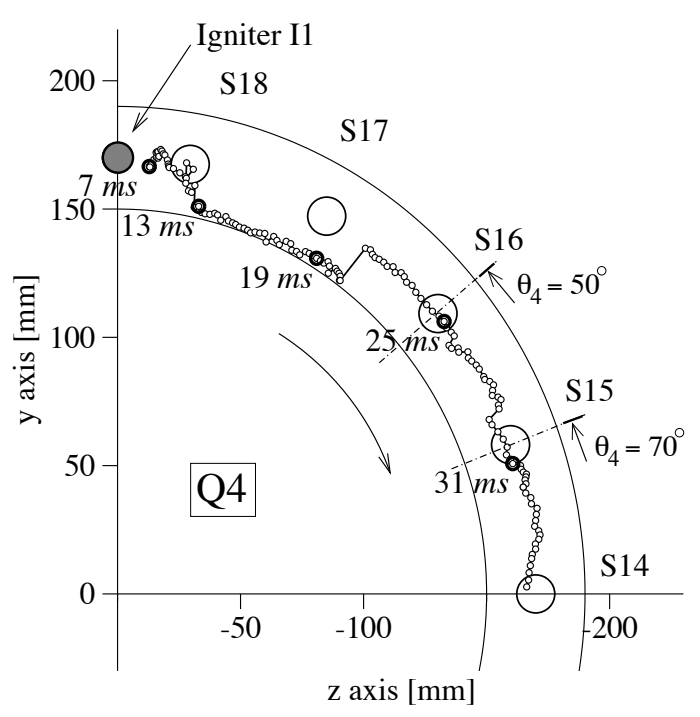

Fig. 14. Axial view of the flame leading point trajectory between $7 \mathrm{~ms}$ and $36.4 \mathrm{~ms}$. $\theta_{4}=50$ and $70 \mathrm{deg}$. are the positions of the two control surfaces used in Fig. 15.

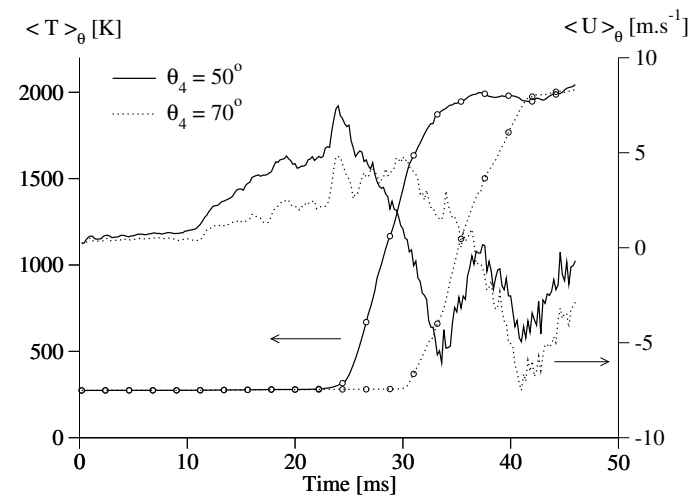

Fig. 15. Time evolution of the flow azimuthal velocity $\langle U\rangle_{\theta}$ (lines) and temperature $\langle T\rangle_{\theta}$ (lines with circles) averaged over an iso- $\theta_{4}$ section for $\theta_{4}=50$ and $70 \mathrm{deg}$. (see Fig. 14). 


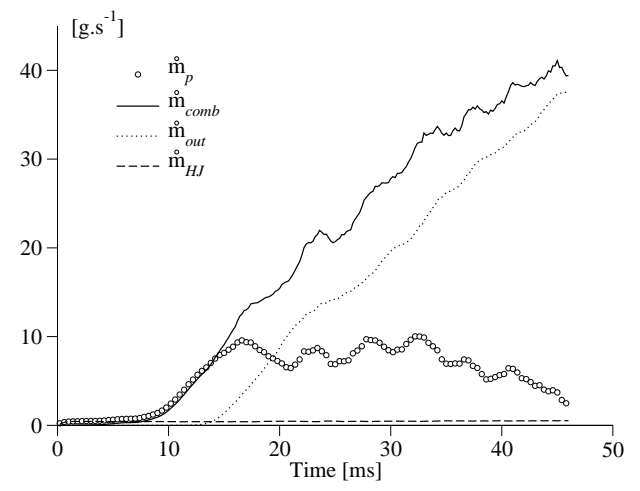

Fig. 16. Time evolution of the products mass balance: temporal variation of the total mass of products $\dot{m}_{p}$, total products reaction rate $\dot{m}_{c o m b}$, mass fluxes through the outlet $\dot{m}_{\text {out }}$ and through the hot igniter jets inlets $\dot{m}_{H J}$.

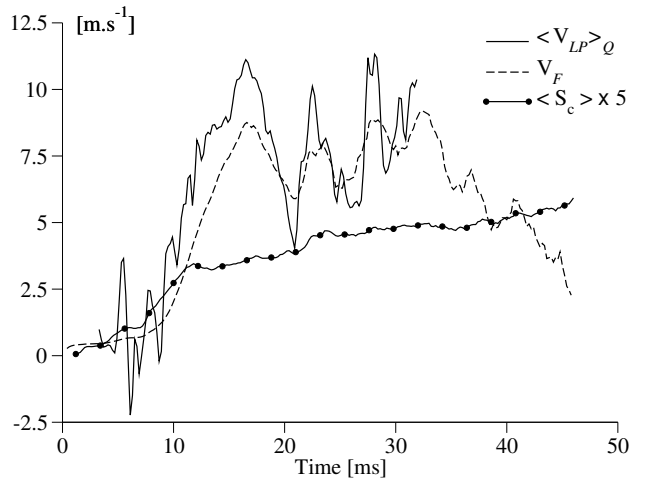

Fig. 17. Comparison between the mean absolute front speed $V_{F}$, the mean leading point azimuthal speed among the four quadrant $\left\langle V_{L P}\right\rangle_{Q}$ and the mean consumption speed $\left\langle S_{c}\right\rangle$ (multiplied by 5 ). 


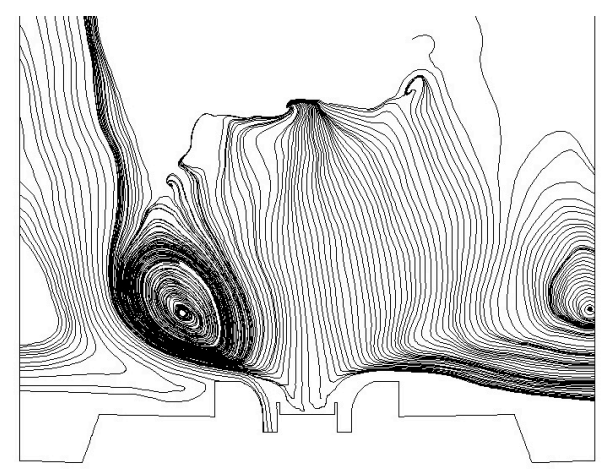

Fig. 18. Time-averaged stream lines in surface $C$ obtained with a single-sector cold-flow calculation.

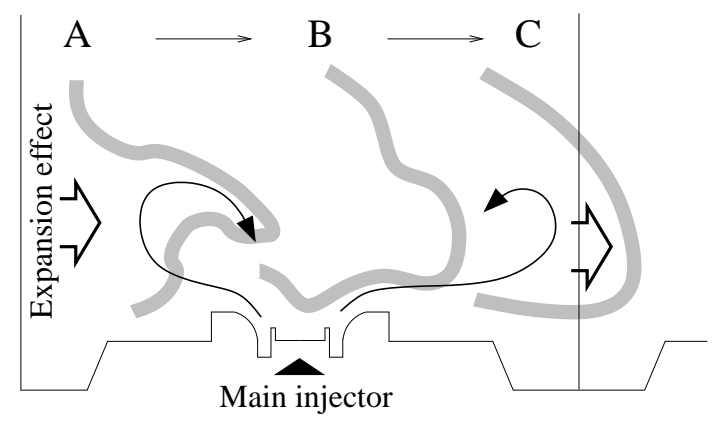

Fig. 19. Three-step evolution of the flame front (thick grey lines) when crossing the main swirled jet. 


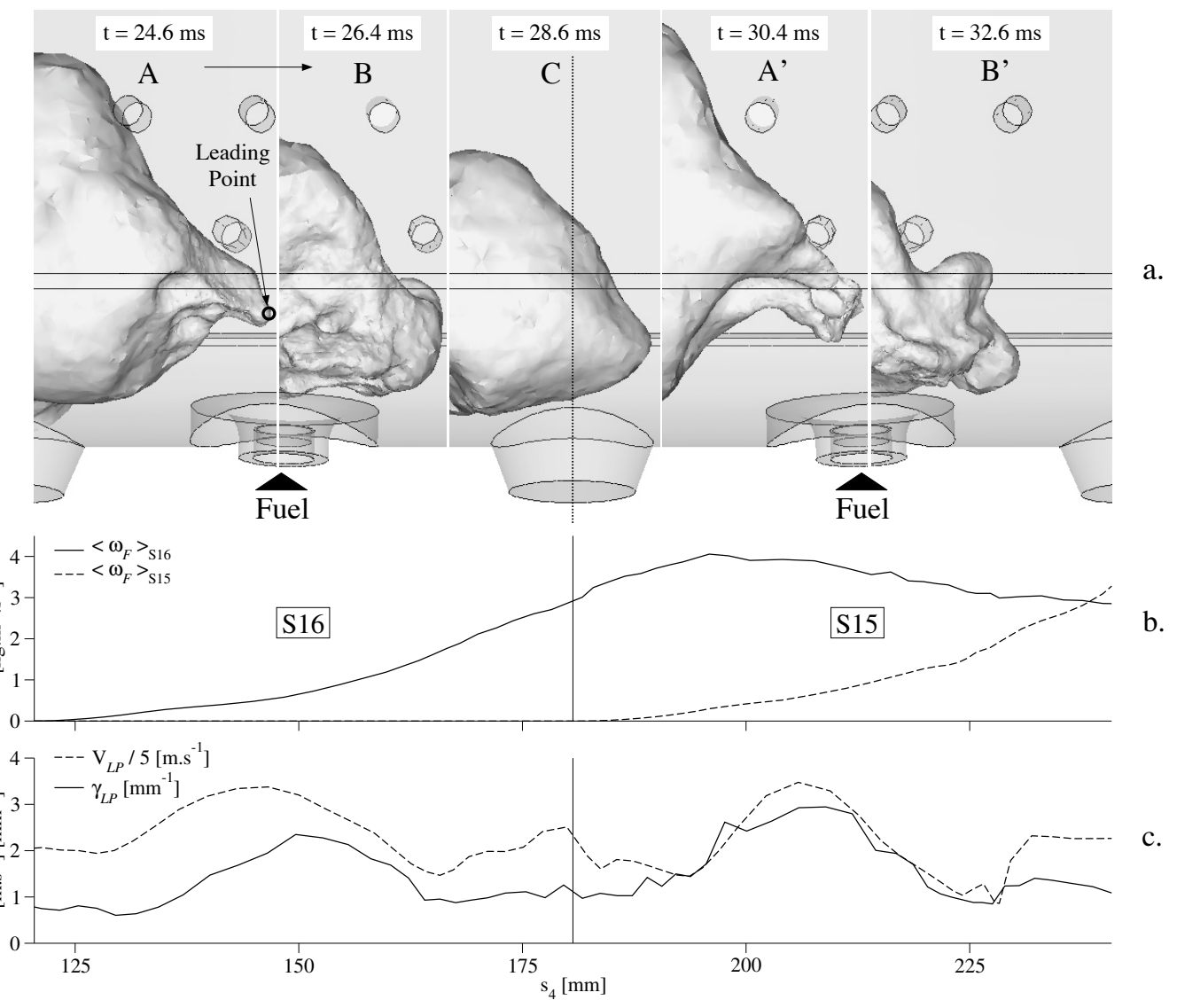

Fig. 20. Radial view of the flame front progress from sector $S 16$ to $S 15$ through 5 successive snapshots (A-C') of the iso-surface of temperature $T=1500 K$ (a.). Mean fuel reaction rate $\left\langle\dot{\omega}_{F}\right\rangle_{S i}$ in sectors $S 15$ and $S 16$ (b.), leading point (LP) azimuthal speed $V_{L P}$ and flame front curvature at $\mathrm{LP} \gamma_{L P}$ (c.) as a function of the azimuthal curvilinear abscissa of the LP $s_{4}$. 


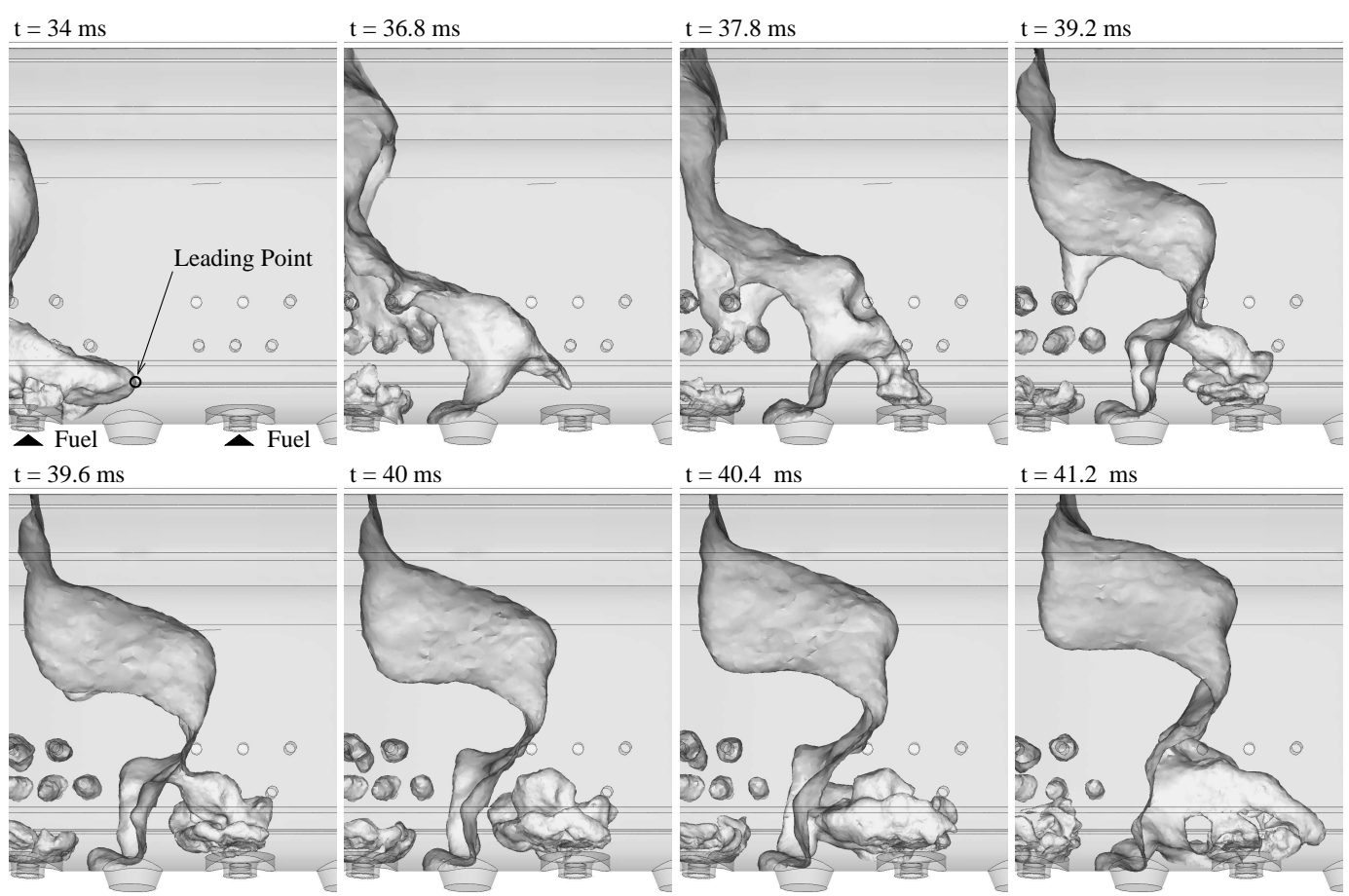

Fig. 21. Progress of the flame front (iso-surface of $T=1500 \mathrm{~K}$ ) from sector $S 15$ to sector $S 14$.

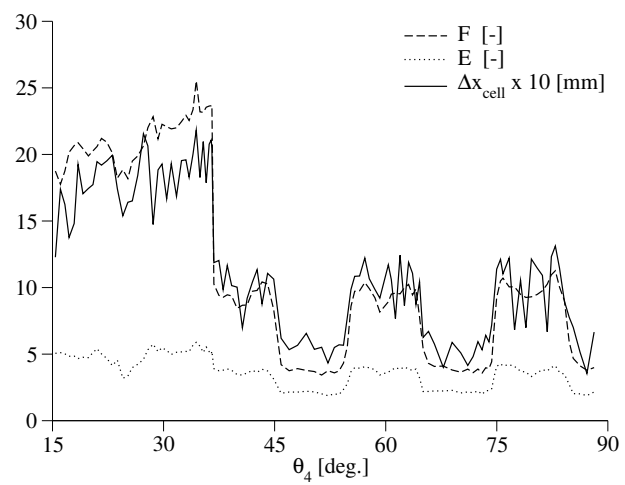

Fig. 22. Thickening factor $F$, efficiency function $E$ and computational cell size $\Delta x_{\text {cell }}$ as a function of the flame leading point azimuthal position in quadrant $Q_{4}$ (see Fig. 8). 


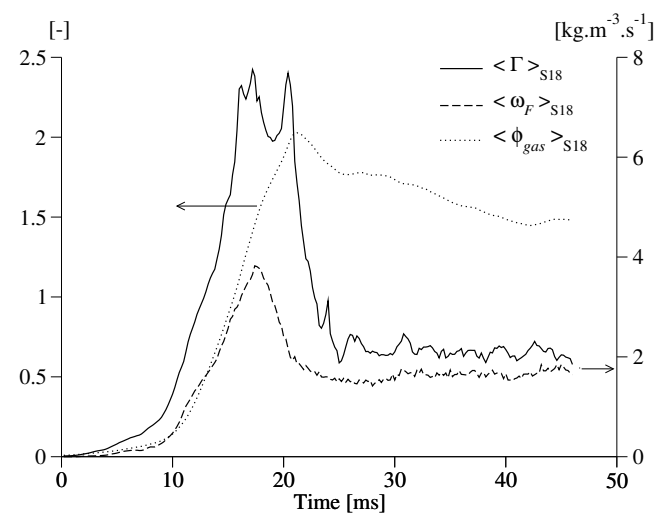

Fig. 23. Temporal evolution of mean quantities in sector $S 18$ : evaporation rate

$\langle\Gamma\rangle_{S 18}$, fuel reaction rate $\left\langle\dot{\omega}_{F}\right\rangle_{S 18}$ and gaseous equivalence ratio $\left\langle\phi_{g a s}\right\rangle_{S 18}$. 


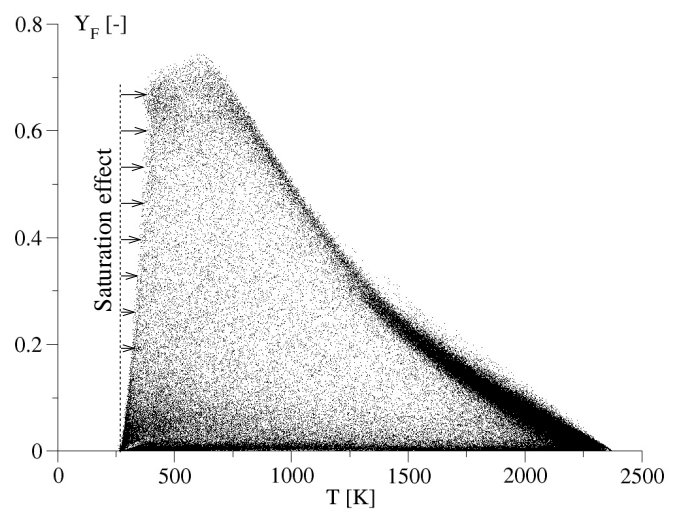

Fig. 24. Scatter plot of gaseous fuel mass fraction versus temperature at $t=28 \mathrm{~ms}$.

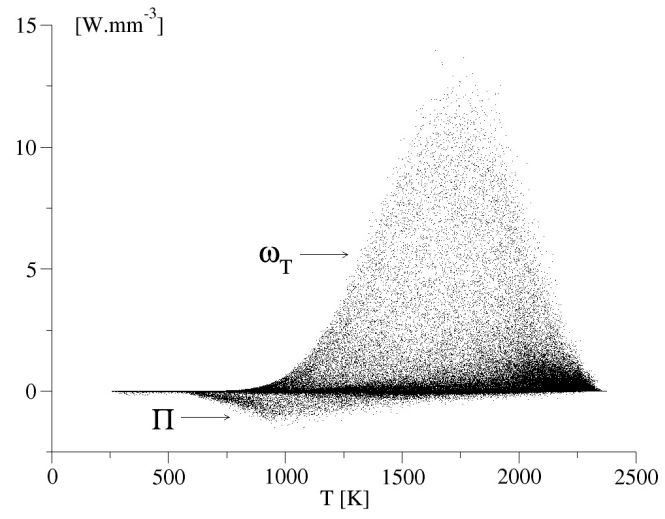

Fig. 25. Scatter plot of heat release $\dot{\omega}_{T}$ and latent heat $\Pi$ versus temperature at $t=28 \mathrm{~ms}$. 


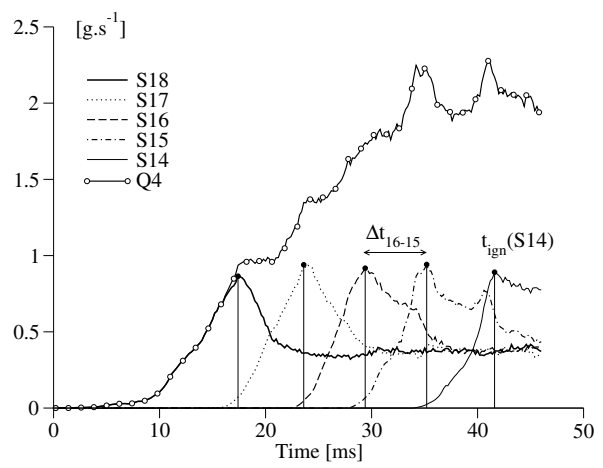

Fig. 26. Time evolution of the total fuel reaction rate into the $Q 4$ quadrant and each single sector of $Q 4$.

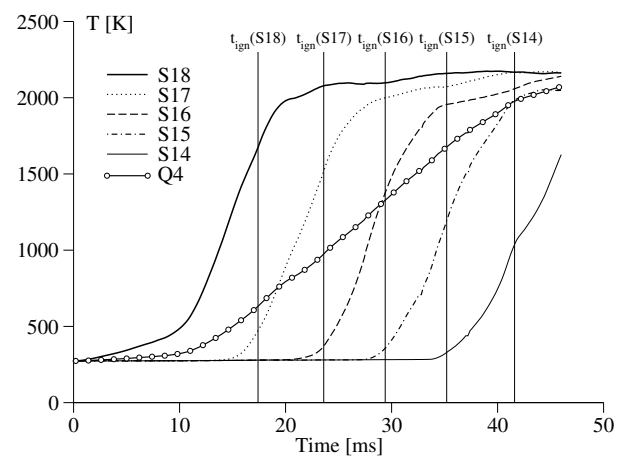

Fig. 27. Time evolution of the mean temperature into the $Q 4$ quadrant and each single sector of $Q 4$. 


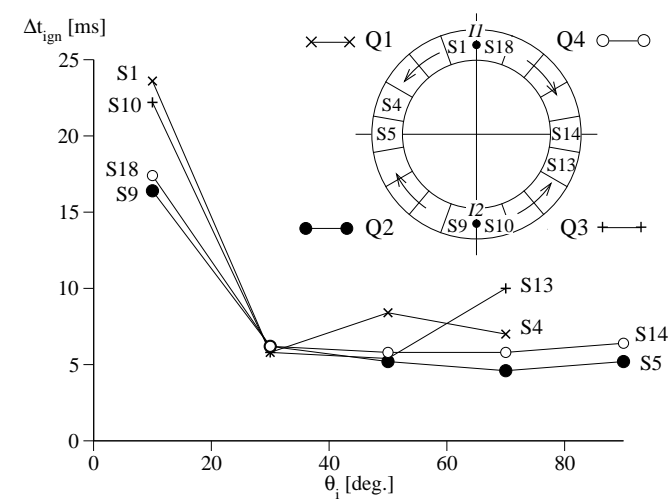

Fig. 28. Flame stabilization time delay between two successive sectors in the four quadrants as a function of the azimuthal sector angle with respect to the igniter (I1 or $I 2)$.

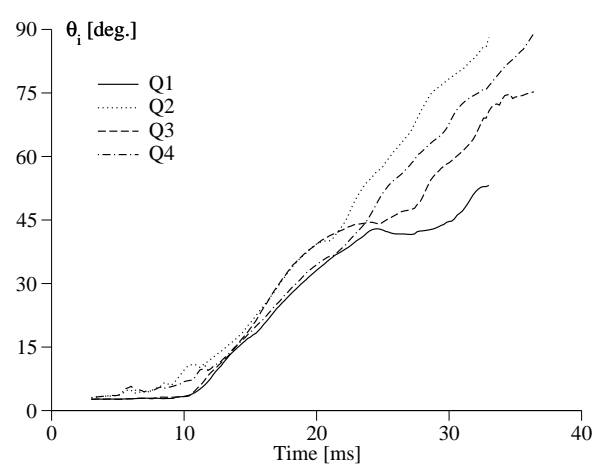

Fig. 29. Time evolution of the azimuthal position of the flame front leading point $\theta_{i}$ in each of the four $Q i$ quadrants. 